\title{
La difusa autonomía. El Colegio del Rosario en los proyectos de universidad pública del siglo XIX colombiano ${ }^{1}$
}

\author{
Julio Gaitán Bohórquez ${ }^{2}$ \\ Universidad del Rosario (Colombia) \\ julio.gaitan@urosario.edu.co
}

Recepción: 20/08/2012

Evaluación: 03/05/2013

Aceptación: 28/06/2013

Artículo de Reflexión

DOI: http:/ / dx.doi.org/ 10.9757 / Rhela. 21.04

\section{RESUMEN}

El artículo explora en fuentes normativas primarias la institucionalidad y la autonomía del Colegio del Rosario de Bogotá durante el siglo XIX, para mostrar sus relaciones con el Estado republicano así como las diversas tensiones de las que fue escenario en el proceso del establecimiento del nuevo sistema educativo, que mediante diversos proyectos y modelos se intentó en medio de grandes contingencias económicas y sociales.

Palabras clave: Revista Historia de la Educación Latinoamericana, universidades siglo XIX, autonomía universitaria, instituciones educativas republicanas, Colegio del Rosario de Bogotá.

1 Este artículo fue escrito en el marco del proyecto de investigación sobre historia institucional del Colegio Mayor de Nuestra Señora del Rosario de Bogotá, financiado por la Universidad del Rosario.

2 Abogado de la Universidad del Rosario, Magíster en Derecho Público de la Universidad Autónoma de Barcelona, Doctor en Evolución de los sistemas jurídicos y nuevos derechos de la Universidad de Lecce (Italia). Director del Programa de Doctorado en Derecho y Profesor del Área de Derecho Constitucional de la Facultad de Jurisprudencia de la Universidad del Rosario, en donde es titular de las cátedras de Historia del Derecho Colombiano y Derecho Constitucional Colombiano. Investigador invitado en el Instituto Max Planck de Frankfurt (Alemania, 2002) y de la Universidad de California en Berkeley (2007). Profesor de Historia del Derecho en la Universidad Autónoma de Barcelona 2004-2005. Exmagistrado Auxiliar Corte Constitucional. Coordinó el Área de Memoria Histórica del Centro Internacional para la Justicia transicional en Colombia. Trabaja temas de Cultura Jurídica, Historia del Derecho y Derecho Constitucional. 
The Diffuse Autonomy. The Rosario Highschool in the projects of the public university in the XIXth Colombian century
A difusa autonomia. O Colégio do Rosário nos projetos de universidade pública do século XIX colombiano

RESUMO

O artigo explora em fontes primarias a institucionalidade e a autonomia do Colégio do Rosário de Bogotá durante o século XIX, para mostrar suas relações com o Estado republicano, assim como as diversas tensões das que foi cenário no processo do estabelecimento do novo sistema educativo, que mediante diversos projetos e modelos se intentou no meio de grandes contingências econômicas e sociais.

Palavras-chave: Revista História da Educação Latino-americana, universidades século XIX, autonomia universitária, instituições educativas republicanas, Colégio do Rosário de Bogotá.
Education, XIXth century universities, university autonomy, Republican educational institutions, Rosario High school Bogota.

\section{INTRODUCCIÓN}

Durante las primeras décadas del siglo XIX comenzó a gestarse un nuevo modelo de universidad que, al modificar las funciones que la vieja institución universitaria cumplía en las sociedades de antiguo régimen, cambió sus prácticas académicas, la organización de sus saberes y los marcos de legitimación de dichas prácticas y saberes.

En efecto, para el caso que nos ocupará, el del Colegio del Rosario de Bogotá, los estatutos proveídos por su fundador a mediados del siglo XVII en forma de Constituciones disponían que su criatura fuera una "congregación de varones insignes, ilustradores de la república con sus grandes letras y con los puestos que merecerán con ellas...". Las instituciones educativas eran un instrumento de la reproducción social, más específicamente, de la reproducción de los caracteres de la sociedad de antiguo régimen. Su función principal era la de mantener la estructura jerarquizada de baja movilidad social, la cual se garantizaba con la admisión exclusiva de aquellos que, luego de los procesos de admisión, demostraran claramente en sus expedientes genealógicos tener limpieza de sangre, es decir, no tener mancha de la tierra y, luego de haber pasado por la institución escolar, asegurar la permanencia de las familias 
tradicionales en los puestos de la burocracia local, a los que se asociaba no solo el prestigio sino también el poder político y económico.

En fin, tanto durante el antiguo régimen como bajo el Estado liberal del siglo XIX, las instituciones educativas fueron centros de poder, por las que circulaba poder y en las que se gestaba el poder. Fueron los viveros en los que se formaban las élites políticas y sociales, lo cual será así hasta la llegada de la universidad de masas en la segunda mitad del siglo XX.

Esta anotada característica las convertía en una de las instituciones más conspicuas como objeto de las disputas entre los diversos proyectos de gestión de la institucionalidad colonial o de creación de la nueva institucionalidad republicana, y quizá a ello se debieron los reiterados intentos provenientes de la orden dominica primero, de la administración colonial luego, y finalmente del Estado republicano, por incorporar el colegio en sus respectivos proyectos.

Es por estas razones por las que el abordaje de la problemática relacionada con la autonomía del Colegio del Rosario durante el siglo XIX impone algunas explicaciones previas relacionadas con el alcance conceptual de la categoría autonomía, pues hay que señalar que no es claro si las resistencias que se presentaron por parte de la Institución a su incorporación al proyecto de Universidad Central o su posterior inclusión en el proyecto de Universidad Nacional, obedecieron a dinámicas de tipo corporativo medieval frente al auge del poder centralizador estatal o si, por el contrario, esas resistencias se fundaron en categorías de derecho moderno, liberal, como el respeto a la propiedad privada, o si los argumentos de resistencia se fundaron en privilegios de estilo corporativo o foral.

Desde la otra orilla del problema, resulta útil el análisis del conjunto de argumentos jurídico-políticos utilizados por el naciente Estado para incorporar la institución a sus proyectos de construcción del sistema universitario nacional, que van desde la asunción del patronato y el correspondiente ejercicio de regalías (instituciones jurídicas de antiguo régimen), hasta la simple ocupación como consecuencia de necesidades o victorias militares. 
Por supuesto que la elaboración del instrumental analítico y la elección del procedimiento metodológico exigen la mayor fidelidad posible al uso que se le dio a esos conceptos, particularmente al de autonomía, en los asuntos referidos al Colegio del Rosario durante el siglo XIX y esa será una obsesión más o menos permanente durante el desarrollo del tema, pues la categoría autonomía puede hacer referencia a múltiples fenómenos como el de autonomía jurisdiccional, académica, económica o disciplinaria, a la intervención de agentes externos en las decisiones de nombramiento y remoción de las autoridades escolares, etcétera.

El trabajo, entonces, se orienta a identificar las formas de relación institucional que vincularon el Colegio Mayor de Nuestra Señora del Rosario con el Estado republicano del siglo XIX, en particular, su articulación a los proyectos de universidad pública durante el mismo período, intentando formular algunas propuestas explicativas de los cambios institucionales que lo afectaron.

Durante el siglo XIX se presentaron numerosas intervenciones del naciente aparato estatal republicano en la institucionalidad del Colegio del Rosario, intervenciones que adoptaron diversas manifestaciones jurídicas y que obedecieron a diversas razones que tuvieron que ver en algunas ocasiones con decisiones de tipo económico, de política educativa o de ejercicio del poder por medio del control de su institucionalidad, entre otras.

Muchas veces las intervenciones estatales en la institucionalidad rosarista modificaron su estatuto jurídico, de tal manera que es necesario el estudio de esas manifestaciones de intervención en orden a la explicación de las características institucionales del Colegio del Rosario durante el siglo XIX.

La claridad acerca de la institucionalidad del Colegio del Rosario durante el siglo XIX facilita la comprensión de otros fenómenos de la vida del Colegio, como los cambios en los planes curriculares y en otros aspectos de la vida académica y económica de la institución, en aquellos aspectos que eran sobredeterminados por disposiciones normativas dictadas desde fuera de sus ámbitos internos de decisión.

El abordaje de la temática de la autonomía o de la dependencia institucional desde el ángulo normativo requirió de algunas precauciones teóricas que la investigación desarrollada no desatendió, como las limitaciones de las 
fuentes normativas para dar cuenta de otros fenómenos institucionales que se mueven al margen de ellas, que son invisibles desde ellas o que, simplemente, se producen desatendiendo sus postulados.

Hecha esta claridad, el estudio resultante intentó una lectura de las fuentes normativas que configuraron la existencia legal del Colegio del Rosario durante el siglo XIX desde una perspectiva teórica que explicara los forcejeos institucionales entre el Estado decimonónico y el Colegio del Rosario, en términos del control de las instituciones del saber como instrumentos políticos que permitían el control de los saberes por parte del Estado, en perspectiva del proyecto de consolidación del proyecto nacional.

Explicar la institucionalidad decimonónica del Colegio del Rosario y su articulación dentro de un proyecto nacional, permite también avanzar en las particularidades de la conformación del modelo universitario colombiano durante el siglo XIX, en particular para resaltar que mientras intentaba liberarse de la tutela de las instituciones eclesiásticas, el modelo universitario neogranadino del siglo XIX se constituyó bajo la tutela estatalista y, en este sentido, su ciencia se desarrolló como ciencia oficial, lejos del otro modelo, el de universidad científica, que comenzaba a configurarse en otros lugares durante la misma época.

En este sentido, la Universidad continuó fungiendo como el vivero privilegiado del funcionariado estatal, que era una función que ya había desempeñado durante la colonia.

\section{Autonomía como categoría durante el siglo XIX}

Autonomía no es un concepto plano o unívoco sino que, por el contrario, representa una categoría de contenido variable que fue invocada con diferentes matices y entendida de manera diversa durante el desarrollo institucional decimonónico del Colegio del Rosario y que dependió en gran medida del juego de fuerzas entre el naciente Estado y la ya, en ese siglo, vieja institución.

La evocación frecuente, dentro de la normativa decimonónica referente al Colegio del Rosario de las Instituciones del fundador, de su voluntad, resalta la importancia del hecho fundacional y de la disputa jurídica que ocurrió 
frente a la orden dominica durante sus primeros años de vida institucional, ${ }^{3}$ dinámica que no fue ajena a la problemática de conformación de las universidades a partir del siglo XIII.

Debe recordarse que las corporaciones de maestros y alumnos surgieron durante el siglo XII dentro de un contexto de desarrollo urbano y que en sentido estricto se conformaron como universidades durante el siglo XIII, el siglo en el que las corporaciones se organizaron para defender sus intereses e instaurar un monopolio en su beneficio. Como lo sostiene Le Goff, ${ }^{4}$ adquirieron su autonomía en disputas contra los poderes eclesiásticos así como contra los poderes laicos, ${ }^{5}$ haciendo frente a la jurisdicción episcopal y a la centralización monárquica, y configurando el poder de la corporación universitaria sobre los privilegios de autonomía jurisdiccional, el derecho de huelga y secesión así como en el monopolio de la colación de grados universitarios. $^{6}$

A partir del siglo XIII se presentó el proceso que Le Goff describe como nacionalización o incluso regionalización de las universidades, pero este fenómeno fue sustancialmente diferente del de nacionalización de las universidades que se llevó a cabo durante el siglo XIX bajo el influjo de las ideas estatistas centralizadoras de corte napoleónico.

En relación con la inclusión del Colegio dentro de los planes y estrategias republicanas de reforma educativa, lo primero que debe destacarse es el uso de un instrumento jurídico de antiguo régimen como el patronato, en la redefinición de las relaciones del poder político con las universidades, como estrategia de tránsito de sistema desde el modelo de relaciones de patronato de los Arzobispos y de la Corona con la Institución, hacia el que regiría las

3 El Colegio Mayor de Nuestra Señora del Rosario fue fundado en 1653 por el dominico Fray Cristóbal de Torres, Arzobispo del Nuevo Reino de Granada Bogotá. En un principio entregó su dirección a la Orden de Predicadores, pero ya en las Constituciones redactadas por el propio fundador para el Colegio, fechadas el catorce de febrero de 1654, declara haber revocado al Rector y Vicerrector (Punto Primero). De la revocatoria se derivó un pleito resuelto casi diez años después, en el que se confirmó la voluntad del fundador de poner al Clero Secular al mando del Colegio, cuyo Rector estaría subordinado a los Arzobispos de Bogotá, que ejercerían el Patronato perpetuo del Colegio (Título II De los Rectores y Constitución I, Perteneciente a los señores Patronos). El Fundador se reservó durante su vida el nombramiento de los rectores y estableció que posteriormente los Colegiales mediante voto eligieran tres personas para proponerle al Arzobispo, quién lo elegiría. El Patrono pediría cuenta al Rector anualmente, quien sería responsable patrimonialmente con sus fiadores por los deterioros de las haciendas, los juros, en fin, de las rentas del Colegio (Constitución I). La fundación del Colegio fue aprobada mediante Cédula Real del 31 de diciembre de 1651.

4 Le Goff, Jacques, Los Intelectuales en la Edad Media (Barcelona: Gedisa, 1996), 70-71.

5 Ibid., 72.

6 Ibid., 79. 
relaciones de la misma Institución con las autoridades republicanas, que culminaría en la adopción del modelo centralizado de corte napoleónico.

Aunque las características jurídicas del patronato se diferenciaban en varios factores de la forma de intervención centralizadora estatal en la Universidad, inaugurada con la creación de la universidad napoleónica, en nuestro caso la asunción del patronato se utilizó por el gobierno de la nueva República para asumir el control centralizado de los establecimientos educativos, entre ellos y de manera principal, del Colegio del Rosario.

Uniformar y centralizar eran las consignas del nuevo esquema de intervención en los establecimientos educativos, objetos extraños o, por lo menos, bastante débiles en el esquema de relación patronal, signado generalmente por caracteres de alteridad y, en alguna medida, de protección del Patrono al establecimiento educativo.

Las decisiones de incorporación del Colegio del Rosario a la Universidad durante el siglo XIX, así como las resistencias a tales decisiones, fueron sustentadas con argumentos de muy diversa índole, como la urgencia de darle entidad real y concreta a la Universidad Central, más allá de las disposiciones legales que la creaban, hasta la necesidad de aprovechar rentas estatales en el impulso a la educación superior o, por otra parte, el imperativo de respetar la voluntad del fundador y restituirlo como un centro de enseñanza tomista.

\section{Relaciones Patronales}

Siguiendo la orientación del régimen Borbónico en lo referente a las relaciones del poder político con las entidades de enseñanza, luego de la ruptura política con España, el Gobierno de la República asumió el patronato, ${ }^{7}$ dirección y gobierno de los establecimientos de educación. ${ }^{8}$ Para los dirigentes políticos de la naciente república era claro el papel estratégico del sistema educativo dentro de los proyectos de construcción nacional y de formación de ciudadanos.

7 El Patronato fue la institución jurídica que estuvo en la base de las relaciones entre la Corona o el Estado y la Iglesia. Se trataba del sistema de intervención del monarca y de las autoridades superiores en los asuntos eclesiásticos cuya legitimidad se asentaba en la idea paternalista de la protección brindada por el Patrono a la institución sobre la cual recaía el patronato

8 Felipe Osorio Racines, Decretos del General Santander. 1819-1821. Decreto 5 de julio de 1820, "Que establece el Patronato en establecimientos educativos por el Gobierno" (Bogotá: Universidad Nacional, 1969), 138. 
El patronato y dirección ejercidos sobre las instituciones educativas había constituido durante la colonia una manifestación o prolongación del sistema de las regalías ${ }^{9}$ ejercidas sobre la Iglesia. Durante la República, el patronato sobre los centros educativos tuvo claros propósitos estratégicos encaminados al control de uno de los lugares productores de legitimidad política, las instituciones del saber, al control de la educación como requisito para el "progreso material y moral de los pueblos", la producción de "verdades científicas" en consonancia con los proyectos estatales, etcétera.

Con la asunción del patronato, que antes de la independencia política ejerció el rey de España, el Gobierno de la naciente República se constituyó en determinador del método, extensión y contenidos de la enseñanza. Simultáneamente desarrolló una celosa labor de fiscalización encaminada a garantizar que se cumplieran las disposiciones referidas al sistema educativo con el propósito explícito de orientar la formación ideológica de los individuos en el sentido requerido por los proyectos republicanos.

Con la emancipación política, el Gobierno de la Gran Colombia asumió el patronato, dirección y gobierno de los colegios establecidos en la República, cualquiera que hubiese sido la característica institucional del establecimiento, en virtud de lo cual intervino desde el primer momento en el manejo de la educación.

Bolívar, como Presidente de la Gran Colombia, promulgó en 1820 un Decreto que disponía que el patronato y dirección de los establecimientos educativos le correspondiera en adelante al Gobierno de la República. Los propósitos expresados en la disposición fueron los de uniformar la enseñanza que se impartía en todo el territorio y el de centralizar su manejo en las manos del Gobierno. ${ }^{10} \mathrm{El}$ ejercicio de dicho patronato correspondería a los vicepresidentes de los departamentos, en tanto agentes del Gobierno, facultad en desarrollo de la cual el vicepresidente del Departamento de Cundinamarca, Francisco de Paula Santander, expidió el "Decreto sobre Patronato de los Establecimientos literarios", en el cual dispuso que las

9 Las regalías eran las atribuciones concretas del poder del Rey en relación con las actividades de la Iglesia que le permitían intervenir en algunos de sus asuntos.

10 Osorio Racines, Felipe. Decretos del General Santander. 1819-1821. Decreto 5 de julio de 1820, "Sobre Patronato y Dirección de Colegios" (Bogotá: Universidad Nacional, 1969), 138. 
cátedras de jurisprudencia civil y canónica, derecho público, filosofía y gramática serían provistas por el Gobierno del Departamento, que nombraría además al Rector, Vicerrector y Pasante de estos establecimientos. ${ }^{11}$

Durante el mismo año de 1820 y en desarrollo de las facultades patronales, el vicepresidente Santander expidió una Reforma al Plan de Estudios para el Departamento de Cundinamarca, que tuvo carácter provisional, mediante el cual reglamentó las cátedras que debían instaurarse en los tres colegios de la capital y en los demás establecimientos públicos del departamento. ${ }^{12}$

\section{El Colegio de Rosario y el Estado decimonónico}

En lo que sigue, se presentará una relación diacrónica, sin mayores pretensiones teóricas, de la normativa que afectó la vida institucional del Colegio del Rosario durante el siglo XIX, a partir de su articulación dentro del Proyecto de Universidad Central en 1826 hasta el último reconocimiento que se hizo de su autonomía en el año 1893, cuyos efectos se mantuvieron de manera inalterada durante todo el siglo siguiente.

\section{Antecedentes}

Es preciso recordar que durante la segunda mitad del siglo XVII, al resolver un pleito entre los Arzobispos de Santa Fe y los regulares Dominicos sobre la autonomía del Colegio frente a la Universidad de Santo Tomás, el Rey dispuso que en lo sucesivo les correspondería perpetuamente a los monarcas de Castilla el patronato del Colegio, quienes lo ejercieron hasta la emancipación política luego de la cual, como se señaló, lo asumieron los Presidentes de la República.

Además del intento de incorporación del Colegio del Rosario a la Universidad de Santo Tomás durante los primeros años de su existencia institucional, durante la colonia se presentó un segundo episodio en el mismo sentido, cuando durante la segunda mitad del siglo XVIII se contempló la incorporación de los colegios al proyecto de creación de la Universidad Pública. En el año 1820 se asumía que los colegios dependían de

11 Felipe Osorio Racines, Decretos del General Santander. 1819-1821. Decreto 8 de julio de 1820, "Sobre Patronato de Establecimientos Literarios" (Bogotá: Universidad Nacional, 1969), 138

12 Ibid., 165. 
la Universidad Central ${ }^{13}$ y, aunque ignoramos los alcances o características precisas de esta dependencia, consistía básicamente en que los egresados de los colegios debían recibir sus grados en la Universidad de Santo Tomás, atribución que subsistió hasta el año 1826, cuando esta facultad de otorgar grados pasó a la Universidad Central.

Aunque durante los primeros años de vida republicana se expidieron algunas normas que facultaron al poder ejecutivo para reformar los colegios ${ }^{14}$ o para organizarlos provisionalmente, ${ }^{15}$ solo en 1826 se reguló de manera integral la articulación de los Colegios del Rosario y de San Bartolomé en el proyecto de Universidad Central.

\section{El Plan de Estudios de 1826}

Teniendo en cuenta el carácter provisional con el que se había expedido el plan de estudios de 1820, Santander dispuso a principios de 1822 la conformación de una comisión que se encargara de formar los proyectos relativos a la instrucción pública, ${ }^{16}$ la que tres meses después de nombrada entregó un Plan general de enseñanza en las escuelas y universidades de Colombia, que sería años después con pocas modificaciones la base fundamental de la Ley de Instrucción Pública de $1826 .{ }^{17}$

Efectivamente, el 18 de marzo de 1826 se sancionó la Ley sobre organización y arreglo de la Instrucción pública, que reprodujo integralmente el proyecto de 1822. En ella se dispuso el establecimiento de universidades centrales en los departamentos de Cundinamarca, Venezuela y Ecuador, las cuales en adelante serían las únicas autorizadas para otorgar grados académicos. Esta ley destinó para el funcionamiento de las universidades los edificios de los

13 Estanislao Vergara Sanz de Santamaría al Rector del Colegio del Rosario. Carta, junio 17 de 1820. Archivo Histórico del Colegio Mayor de Nuestra Señora del Rosario (AHCR) Vol. 22. Fol. 341-343

14 Ley 20 de junio de 1821, que dio al Poder Ejecutivo la facultad de establecer nuevos colegios o casas de educación, reformando las que existían, así como la de formar el plan uniforme de estudios y arreglar todo lo concerniente a la educación pública. En Compilación de Normas sobre la Educación Superior. República Neogranadina, Volumen II, Parte I (Bogotá: ICFES, 1974), 143

15 Circular de Octubre 20 de 1823, José Manuel Restrepo, por la cual se organizaron provisionalmente los colegios y Universidad Central de Bogotá. En Compilación de Normas sobre la Educación Superior. La República Neogranadina. Vol. II. Parte I (Bogotá: ICFES, 1974).

16 Los integrantes de la comisión fueron el Secretario de Relaciones Exteriores, el Senador Jerónimo Torres, el Prebendado Francisco Guerra y los Doctores Santiago Pérez Valencia y Benedicto Domínguez. Decreto enero 5 de 1822. En Compilación de Normas sobre la Educación Superior. La República Neogranadina. Vol. II. Parte I (Bogotá: ICFES, 1974), 143.

17 Proyecto para el arreglo de la enseñanza pública formado por la Comisión encargada del Plan de instrucción general de la República de Colombia, Archivo Legislativo del Congreso de Colombia (ALC), 1821-1822. Senado. Asuntos Varios. V Bis. Fol. 196-203 vto. 
conventos suprimidos ${ }^{18}$, así como los edificios de propiedad de la nación cuyo uso el Poder Ejecutivo creyera conveniente para su funcionamiento. ${ }^{19}$ En desarrollo de tal facultad, el Vicepresidente Santander destinó para el uso de la Universidad Central de Bogotá, entre otros, el edificio del Colegio San Bartolomé. $^{20}$

En lo que atañe al Colegio del Rosario, su autonomía fue ostensiblemente afectada mediante una disposición de la misma ley que preveía que si en los edificios inicialmente destinados a la Universidad no hubiese locales suficientes para establecer todas las cátedras, podrían los catedráticos de medicina impartir provisionalmente sus lecciones en el Colegio del Rosario. Las cátedras de idiomas, ciencias naturales, medicina, jurisprudencia y teología del Rosario y San Bartolomé y las rentas de las que gozaban sus catedráticos se destinaron al funcionamiento de la Universidad Central de Bogotá, que en adelante proveería las vacantes, se debe entender que los catedráticos de las clases expresadas eran catedráticos de la Universidad. ${ }^{21} \mathrm{De}$ esta manera el edificio, las cátedras, los catedráticos y las rentas del Colegio del Rosario quedaron afectados al funcionamiento de la Universidad Central de Bogotá. ${ }^{22}$

En adelante, en todo lo que tuviera relación con los planes de estudios, los rectores de los colegios dependerían de la Universidad y las enseñanzas impartidas en ellos estarían sometidas a las directrices académicas de esta. Aunque se les reconoció independencia en lo relativo a economía, gobierno y régimen interior, ${ }^{23}$ la regulación para su funcionamiento fue lo suficientemente minuciosa como para no permitir mayor margen de maniobra a las autoridades escolares de cada uno de los establecimientos que antes eran independientes de la Universidad.

Según lo dispuesto por el Plan de Estudios, las cátedras de uno y otro colegio se entenderían dadas por la Universidad y las oposiciones se harían

18 Con el fin de "conservar la disciplina eclesiástica" se habían mandado a suprimir los conventos en los que hubiera menos de 8 regulares. Ley de 6 de agosto, 1821. Codificación Nacional de todas las leyes de Colombia desde el año de 1821, hecha conforme a la ley 13 de 1912, (Codificación Naciona), 21.

19 Ley 18 de marzo, 1826. Artículo 73. En Compilación de Normas sobre la Educación Superior. La República Neogranadina, Vol. II. Parte I (Bogotá. ICFES, 1974), 168-180,

20 Decreto del 20 de Octubre, 1826. Gaceta de Colombia No. 266 del 19 de Noviembre, 1826. Trimestre 22.

21 Artículos 5, 7 y 8 del Decreto 20 de octubre, 1826.

22 Mediante otro decreto del mismo 20 de octubre de 1826 se ordenó el establecimiento de la Universidad Central de Bogotá. Gaceta de Colombia No. 266 del 19 de noviembre, 1826. Trimestre 22.

23 Decreto 5 de Marzo, 1827, Artículo 2. En: Compilación de Normas sobre la Educación Superior. La República Neogranadina, Vol. II. Parte I (Bogotá: ICFES, 1974), 180 - 181. 
en cada uno de ellos siguiendo las reglas prescritas en el mismo Plan. Los nombramientos deberían recaer en los hijos del respectivo colegio y cada establecimiento se encargaría de pagar a sus catedráticos las asignaciones que recibían cuando se publicó el Plan de Estudios. Posteriormente se dispuso que los rectores de los colegios se turnaran en el rectorado de la Universidad.

En adelante solamente podrían obtenerse grados académicos en las universidades mediante las formalidades establecidas en el Plan de Estudios, que posteriormente debería expedir el Poder Ejecutivo en desarrollo de las facultades conferidas para tal fin mediante un decreto que profirió el Congreso en la misma fecha. ${ }^{24}$

En efecto, la ley dispuso que mediante un decreto especial se expidiera posteriormente por el mismo Legislativo el plan sobre establecimiento de escuelas y universidades, comprensivo del "arreglo uniforme de la enseñanza que debía seguirse en ellas". ${ }^{25}$ Sin embargo, ante las dificultades para proferirlo, debido a la falta de información suficiente en relación con el estado de la instrucción pública, el Congreso decidió delegar en el Poder Ejecutivo la formación y ejecución de un plan provisional. ${ }^{26}$

\section{Establecimiento del Plan de Estudios}

En desarrollo de la delegación hecha por el Congreso al Poder Ejecutivo, el Vicepresidente Santander, encargado de la Presidencia, dictó el 3 de octubre del mismo año el Plan general de las escuelas primarias de educación, colegios y universidades, ${ }^{27}$ siguiendo la línea de reglamentación minuciosa que caracterizó la última etapa del Virreinato ${ }^{28}$ y en consonancia con la tendencia general que tuvieron otros planes de estudio como el Proyecto preparado por Condorcet para la Asamblea Nacional Francesa en 1792, ${ }^{29}$ las Bases para la formación de un plan general de instrucción pública, redactado

24 Decreto de 18 de Marzo, 1826, “que autoriza al poder ejecutivo para formar el plan de estudios". En Luis Horacio López Domínguez, Obra Educativa de Santander, Vol. III (Bogotá: Banco de la República. 1990), 382-383.

25 Ley 18 de Marzo, 1826, artículo 2 . En Compilación de Normas sobre la Educación Superior. La República Neogranadina, Vol. II, Parte I (Bogotá: ICFES, 1974), 168-180.

26 Decreto 18 de Marzo, 1826, "que autoriza al Poder Ejecutivo para formar el plan de estudios". En Obra Educativa de Santander, Vol. III, Luis Horacio López Domínguez (Bogotá: Banco de la República, 1990), 382-383.

27 Decreto 3 de Octubre, 1826, "sobre el plan de estudios" en: Codificación Nacional, Tomo VII, 401-451.

28 Jaime Jaramillo Uribe, "El Proceso de la educación. Del Virreinato a la época contemporánea”. En Manual de Historia de Colombia. Tomo III (Bogotá: Procultura. Instituto Colombiano de Cultura. (3ª. Ed.), 1984).

29 Nicolás De Caritat, Marqués de Condorcet, La Instrucción Pública (Catalonia: Eumo Editorial, 1996). 
por Jovellanos para la Junta Central en 1809 y el Plan de estudios elaborado por los liberales españoles en $1821 .^{30}$

La concepción de la instrucción como base de la felicidad y prosperidad de los pueblos y, dentro de ella, la primacía de las ciencias útiles o prácticas, eran ideas centrales del pensamiento pedagógico de Jovellanos y de las corrientes ilustradas del siglo XVIII que influyeron en la redacción del Plan de Estudios de 1826, y que permiten constatar la existencia de una continuidad programática entre el hecho cultural más importante del siglo XVIII en la Nueva Granada, la Expedición Botánica, y las reformas educativas contenidas en las primeras medidas republicanas. Las orientaciones naturalistas y el despertar de la atracción por la experimentación como fundamento de construcción del conocimiento se pusieron de moda en las instituciones del saber neogranadinas. ${ }^{31}$

Otros principios que informaron tanto los planes ilustrados como los republicanos fueron la gratuidad, uniformidad de método, prescripción de obras, uso de la lengua castellana, práctica de exámenes públicos y certámenes literarios así como una especial preocupación por el cuidado y dotación de bibliotecas y gabinetes. La conformación de un sistema nacional centralizado de educación, de estructura jerárquica, a cuya cabeza estuviese un órgano colegiado de dirección, la voluntad de que los textos para la enseñanza fuesen los mismos en todo el Reino para evitar las diferencias de criterio que surgirían de la consulta de diferentes libros, son algunos de los legados que recibieron los planes de educación neogranadinos de las concepciones que sobre la organización del sistema educativo tenían las corrientes liberales de comienzos de siglo y que tuvieron, para nuestro caso, su primera manifestación constitucional en el artículo 368 de la Constitución gaditana, la cual dispuso que el plan general de enseñanza fuese uniforme en todo el reino.

El Plan de Estudios de 1826 dispuso que la enseñanza de las cátedras de filosofía o ciencias naturales, de medicina, de jurisprudencia o teología que

30 Antonio Álvarez de Morales, Decreto LXXXI de 29 de junio, 1821. "Reglamento General de Instrucción Pública", en Génesis de la universidad española contemporánea (Madrid: Instituto de Estudios Administrativos, (1972).

31 Acerca de la Expedición Botánica como expresión de una política científica por parte de la Corona ilustrada y su línea de centralización de la ciencia, su control, unidad y modernización, ver Mariano Peset, "José Celestino Mutis y la Ciencia Novogranadina". En Claustros y Estudiantes. Congreso internacional de historia de las universidades americanas y españolas en la edad moderna, dirección y prologo Mariano Peset (Valencia: Facultad de Derecho de la Universidad de Valencia, 1989, Vol. II), 199-212. 
se impartían en los colegios existentes en las ciudades en las que se creaban universidades centrales o departamentales se incorporasen a estas con todas sus rentas y que, en adelante, fueran provistas por la misma universidad. Los colegios conservarían su denominación y en ellos seguirían impartiéndose las clases de literatura, bellas letras e idiomas. ${ }^{32}$

En adelante la Universidad conferiría los grados académicos a quienes, además de haber aprobado los cursos necesarios, demostraran públicamente tener la instrucción y aptitud exigidas para cada grado, que los habilitaría tanto para efectos civiles como eclesiásticos. En lo sucesivo no habría otros grados que los de bachiller, licenciado y doctor en jurisprudencia, en medicina y en teología. Se suprimieron por lo tanto todos los grados en filosofía y en derecho canónico. ${ }^{33}$

El Rector del Colegio del Rosario, Juan Fernández de Sotomayor, entre numerosos reparos que hizo al Plan, criticó la centralización de la enseñanza superior en las universidades de Bogotá, Quito y Caracas, porque excluía a los colegios de provincia y cantón de la posibilidad real de poder ofrecer cursos de jurisprudencia y medicina. ${ }^{34}$

Pero, al año siguiente de la promulgación del Plan de estudios, la Gaceta de Colombia, órgano de las publicaciones oficiales, daba cuenta de las dificultades en el establecimiento de la Universidad de Bogotá. ${ }^{35}$ Pronto el Congreso autorizó al Poder Ejecutivo para que hiciese las reformas que estimase convenientes, como crear subdirecciones de estudios en los lugares que no fuesen capital de departamento y conceder a los colegios provinciales la facultad de establecer las cátedras reservadas por el Plan a las Universidades. $^{36}$

No obstante, durante el mes de octubre de 1827 se realizaron los certámenes literarios de la Universidad Central de Bogotá correspondientes a las clases de física, legislación universal, filosofía, matemáticas, historia natural, economía

32 Artículo 25 Decreto 3 de octubre, 1826, "sobre el plan de estudios". En Codificación Nacional. Tomo VII, 401-451.

33 Artículo 50 del Decreto 3 de octubre, 1826. Acerca del sentido de estas reformas ver Julio Cesar Gaitan Bohorquez, Huestes de Estado. La formación universitaria de los juristas en los comienzos del Estado Colombiano (Bogotá: Universidad del Rosario, 2002).

34 "Respetuosa [sic] esposición que el Rector del [sic] Colejio del Rosario hace al Supremo Congreso sobre los atracos y perjuicios que causa a la educación pública la ley orgánica de estudios y el arreglo que por ella ha sido hecho”. ALC Senado. 1827. Tomo XLI. Peticiones, Fol. 164 a 181.

35 Gaceta de Colombia No. 278 del 11 de febrero, 1827.

36 Gaceta de Colombia No. 314 del 21 de octubre, 1827 
política, ${ }^{37}$ instituciones canónicas, filosofía, derecho civil romano y patrio, derecho internacional, teología, clínica, anatomía, derecho constitucional e idiomas. $^{38}$

En 1828 la falta de edificio propio en el que pudiese habitar el Rector y se impartiesen las lecciones a los cursantes había impedido el funcionamiento de la universidad pública en los términos previstos en el Plan de Estudios lo cual, se adujo, generaba un "grave desorden tanto en las lecciones, que ordinariamente no se dan con exactitud por los catedráticos, como en la educación [sic] relijiosa, moral i literaria de los jóvenes", argumentos que condujeron, luego de apenas dos años de su vigencia, a que se decretase el restablecimiento de los colegios de San Bartolomé y el Rosario al estado que tenían cuando se publicó el Plan de Estudios de tres de octubre de 1826.

Se reconoció de esta manera la situación de hecho que venía presentándose en el funcionamiento de la Universidad, es decir, que era apenas formal, pues en la práctica eran los Colegios incorporados los que habían funcionado como tal.

Sin embargo, se regularon oficialmente las cátedras que debía haber en cada colegio y se dispuso que los profesores de estos lo serían también de la Universidad, esto es, habría en cada colegio una sola cátedra de filosofía y matemáticas, cuidando que no se abriesen cursos de filosofía simultáneamente durante un mismo año en los dos colegios, una de derecho civil de romanos comparado con el patrio, una de derecho canónico, una de derecho internacional y economía política y dos de teología. ${ }^{39}$

El Decreto reprodujo en buena medida disposiciones ya adoptadas por el Plan de Estudios, como que la provisión de cátedras de uno y otro colegio se haría por la Universidad, debiendo recaer los nombramientos en los hijos del respectivo colegio, mediante el procedimiento de oposición y en la forma prescrita en el plan de estudios, reservando sin embargo la provisión de cátedras por la primera vez al Gobierno, sin necesidad realizar tal procedimiento de oposición o concurso.

37 Gaceta de Colombia No. 319 del 25 de noviembre, 1827.

38 Gaceta de Colombia No. 322 del 16 de diciembre, 1827.

39 Decreto del 29 de noviembre, 1828, "Por el cual se adicionan algunas disposiciones del Plan [sic] jeneral de estudios". Gaceta de Colombia 390 del 14 de diciembre, 1828. Trimestre 31. 
Se percibe en el texto de la disposición un celo particular por separar las actividades de los colegios: cada uno pagaría a sus catedráticos, tendría sus actos literarios privados y aunque todos los certámenes y exámenes públicos se llevarían a cabo en la capilla de la Universidad, debería separarse a los cursantes de uno y otro establecimiento.

Dispuso el Decreto que en adelante no se nombraría Vicerrector de la Universidad, pues el cargo lo desempeñarían los rectores de los dos colegios, quienes se alternarían en el cargo por períodos de dos años. Finalmente, declaró suspendidos todos los artículos de la ley de 18 de marzo y del Decreto del 3 de octubre de 1826, mientras la Universidad Central adquiriese su edificio propio o independiente para su funcionamiento. ${ }^{40}$

\section{Nuevas Revisiones al Plan de estudios}

En 1829, teniendo en cuenta los informes dirigidos al Gobierno por algunas subdirecciones y por la Dirección General de Estudios, en los que señalaban que el plan general de 3 de octubre de 1826 contenía disposiciones que no habían podido practicarse o que no habían producido los efectos benéficos que se había propuesto, el Gobierno dispuso su adición. ${ }^{41}$ Sin embargo, lo dispuesto esta vez no afectó el esquema de relaciones que entre la Universidad Central y el Colegio del Rosario había establecido el Plan de Estudios de 1826.

La Ley 30 de mayo de 1835 declaró expresamente la vigencia del plan general de enseñanza pública de 1826 y derogó las demás leyes y decretos que regulaban la enseñanza pública cuya vigencia no se declarase expresamente en ella. De esta manera, las cátedras de jurisprudencia del Rosario y el San Bartolomé continuaron incorporadas a la Universidad Central. El Presidente de la Nueva Granada continuó creando cátedras, ${ }^{42}$ nombrando al Rector, Vicerrector y pasante del Colegio. ${ }^{43}$ En este mismo año el Rector y los catedráticos del Colegio del Rosario solicitaron al Poder Ejecutivo que,

40 Decreto del 29 de noviembre de 1828, "Por el cual se adicionan algunas disposiciones del Plan [sic] jeneral de estudios". Gaceta de Colombia 390 del 14 de diciembre, 1828. Trimestre 31. Artículos 3, 7, 15 y 17.

41 Decreto de diciembre 5 de 1829. Gacetas de Colombia. No. 469 del 13 de junio, 470 del 20 de junio, 471 del 27 de junio y 474 del 18 de julio, 1830 .

42 Decreto Marzo 20, 1837, en Registro Oficial de la Nueva Granada. 1837, 13.

43 Decreto 24 de Diciembre, 1838. 
al hacer el arreglo de las cátedras de la Universidad, mantuviera las que venían dictándose en él. ${ }^{44}$

En lo que se refiere a la vigilancia financiera del Colegio, una resolución de la Secretaría del Interior proferida en 1835 aclaró que, aunque las universidades y colegios se encontraban en todo bajo la inspección del poder ejecutivo, la inmediata fiscalización de sus cuentas le correspondía a la Contaduría General de Hacienda. Dichas cuentas, después de fenecidas cuando y por quien correspondiese, debían pasarse al Contador de la provincia dentro de cuyo territorio estuviera asentado el correspondiente establecimiento, ${ }^{45}$ lo que al parecer se cumplió regularmente. ${ }^{46}$

\section{El Colegio del Rosario y la Universidad del Primer Distrito}

La Ley 16 de mayo de 1840 encargó la dirección de los colegios a las Cámaras Provinciales ${ }^{47}$ otorgándoles atribuciones para dictar ordenanzas y resoluciones sobre recaudación, administración y contabilidad de sus rentas y fondos, sobre creación, supresión, dotación y provisión de cátedras y todo lo demás relacionado con la educación, ${ }^{48}$ en particular, las facultó expresamente para reglamentar los contenidos de la enseñanza que se impartiera en los colegios existentes en la respectiva provincia. ${ }^{49}$ Posteriormente se ampliaron estas facultades otorgándoles las de dictar reglas sobre la organización y dirección de estos establecimientos, inversión de sus fondos, creación, nombramiento, supresión y destitución de los superiores y de los demás empleados. ${ }^{50}$

$\mathrm{Al}$ año siguiente, la ley de 15 de mayo de 1841 declaró que los cursos que habilitaban para obtener grados en jurisprudencia y en medicina debían cursarse y aprobarse en las universidades. ${ }^{51}$ Posteriormente, en su memoria al Congreso de 1844 en calidad de Secretario de Instrucción, Mariano Ospina

44 Archivo General de la Nación (AGN), Sección República. Fondo Instrucción Pública. Tomo 111. Fol. 646.

45 José M. Mantilla, al Rector del Colegio del Rosario, comunicándole que el Colegio está en todo bajo inspección de las cuentas que las debe pasar al Contralor de la Provincia (Bogotá: Carta de 1835, Archivo Histórico del Colegio Mayor de Nuestra Señora del Rosario (AHCR), Vol. 21. Fol. 136-137).

46 Luis M. Silvestre, Contador General. Documento de 8 de marzo de 1837, Bogotá, transcribiendo la resolución emitida por la Cámara de Provincia de Bogotá, aprobando las cuentas presentadas por los rectores interinos del Colegio del Rosario Don Manuel Cañarete y Don José María Duque Gómez, de agosto a octubre, 1835. AHCR, Vol. 31 Fol. 136.

47 La Constitución del Estado de la Nueva Granada de 1832 dividió el territorio de la República en Provincias, las cuales tuvieron, aparte del Gobernador, un órgano colegiado de administración denominado Cámara Provincial.

48 Ley 16 de Mayo, 1840.

49 Decreto 7 de Julio, 1840, en ejecución de la ley 16 de mayo de ese año. En Registro Oficial año de 1840, 14.

50 Ley 15 de Mayo, 1841, artículo 1.

51 Ley 15 de mayo, 1841. Artículo 3. 
Rodríguez afirmaría que esta decisión de reservar a las universidades los estudios propios de abogados, médicos y teólogos había tenido el propósito de redireccionar los fondos de los establecimientos provinciales y de los demás establecimientos menores hacia la enseñanza secundaria, con la intención de "formar hombres aptos para las profesiones que la sociedad exige", esto era, "ciencias matemáticas, físicas y naturales de una utilidad más positiva; y de conocimientos industriales." ${ }^{52}$

Las reformas impulsadas por Ospina estuvieron destinadas a promover un giro hacia las profesiones prácticas, en contra de lo que se consideraba como enseñanzas tradicionales.

Las referidas disposiciones que, por una parte, les daba a los colegios el carácter de establecimientos provinciales $\mathrm{y}$, por otra, reservaban la posibilidad de ofrecer cursos de medicina y jurisprudencia a las universidades, afectaban gravemente tanto a los alumnos de los colegios como a la Universidad Central, debido a que en los años anteriores, en los que esta no había contado con fondos propios, se habían incorporado a ella las cátedras de facultades mayores pertenecientes al San Bartolomé y al Rosario, las cuales en adelante, como pertenecientes a colegios provinciales en virtud de la ley 16 de mayo de 1840, no servirían para obtener grados universitarios y, por lo tanto, la Universidad quedaba, en razón de esta medida, desprovista de las cátedras con las que contaba ${ }^{53}$ y los estudiantes sin posibilidad legal de hacer valer como estudios universitarios los cursados en los colegios.

Desde luego, esta situación no solo provocó las protestas de las cámaras provinciales sino que, además, el 9 de marzo de 1842 los cursantes de jurisprudencia de los colegios de San Bartolomé y el Rosario le solicitaron al Rector dela Universidad que pusiera en conocimiento dela Junta deInspección y Gobierno de esta los problemas surgidos a raíz de la expedición de la Ley de 15 de Mayo de 1841, en virtud de la cual solo habilitaban, para obtener grados académicos, aquellos cursos que se ganasen en las universidades de la República, de lo cual se derivaban igualmente serios inconvenientes a

52 Antonio José Uribe, “La Reforma Universitaria”. Revista de la Instrucción Pública de Colombia 79. Tomo XIII (1903): 557588 .

53 Doris Wise de Gouzy, "Esposición que el Secretario de Estado en el Despacho del Interior y Relaciones Esteriores del Gobierno de la Nueva Granada [sic] dirije al Congreso Constitucional el año de 1842”. 1842. Sección 4a. Instrucción Pública, en Antología del Pensamiento de Mariano Ospina Rodriguez. Tomo I. (Bogotá: Colección Bibliográfica del Banco de la República, 1990). 
quienes estaban terminando su carrera, pues la Universidad no solo carecía de cátedras sino que también adolecía de falta de fondos para su existencia formal y, por lo tanto, resultaba que los estudios de jurisprudencia y medicina cursados durante el último año en los colegios provinciales de San Bartolomé y el Rosario habían quedado sin reconocimiento legal.

Consideraban los estudiantes en su petición que debían habilitárseles las asignaturas ya cursadas en los colegios, por constituir estos la Universidad y porque los estudios hechos en ellos siempre se habían reputado universitarios, por cuanto los exámenes de las materias cursadas en ellos se presentaban al fin de cada año en la Universidad Central y los estudiantes eran allí aprobados o reprobados por la junta de catedráticos examinadores, a lo cual agregaron que era claro que si estos establecimientos pudieran concebirse como instituciones enteramente independientes de la universidad, ella nada tendría que ver con los catedráticos ni con los actos [certámenes] privados de aquellos. ${ }^{54}$

En la misma fecha la referida solicitud fue puesta a consideración de la Junta de Gobierno de la Universidad, la que a su vez resolvió someter al conocimiento del legislador un informe sobre el caso, el cual fue remitido dos días después a la Cámara de Representantes.

En el informe, el Rector de la Universidad manifestó los inconvenientes que se derivaban de lo dispuesto por el artículo tercero de la ley adicional a la orgánica de estudios, que reservaba a las universidades la facultad de ofrecer estudios de jurisprudencia. Supuso este artículo, dijo el Rector, que en la Universidad Central funcionaban las cátedras de jurisprudencia conforme al artículo 16 de la ley 11 de mayo de 1840. Pero fue, precisamente por falta de fondos para crearlas, que algunas disposiciones anteriores habían reputado los estudios de jurisprudencia hechos en el Rosario y el San Bartolomé como cursos ofrecidos por la Universidad para efectos de obtener grados académicos. Si se inhabilitaban las cátedras de los colegios, resultaría que los hechos en el último año no serían válidos y los estudiantes tendrían que continuar sus carreras en Cartagena o en Popayán. ${ }^{55}$

54 ALC, 1842. Cámara de Representantes. Peticiones XII. Fol. 84.

55 ALC 1842. Cámara de Representantes. Peticiones XII. Fol. 84 y 82. 
El 16 de marzo de 1842 Mariano Ospina, como Secretario de Estado en el Despacho del Interior y Relaciones Exteriores, dio cuenta a la misma Cámara de Representantes de una solicitud hecha el 21 de octubre de 1841 por el Rector del Colegio del Rosario al Poder Ejecutivo ${ }^{56}$ en la que pedía que se declarasen nacionales los colegios del Rosario y San Bartolomé, habilitándolos para que los cursos que se tomaran en ellos sirviesen para obtener grados universitarios como si se hubieran cursado en la Universidad.

El Poder Ejecutivo negó la petición argumentando que no tenía competencia para hacerlo porque los colegios se encontraban sometidos a las disposiciones legales del 15 de mayo de 1841 y del 16 de mayo de 1840, que les asignaba el carácter de establecimientos provinciales sometidos a la competencia reguladora de la Cámara Provincial. Sin embargo, el Ejecutivo se comprometió a presentar la solicitud al legislador, lo que hizo en su oportunidad proponiendo a la Cámara de Representantes, dentro del proyecto del plan de estudios superiores, la reunión en un solo establecimiento de la Universidad Central, el Museo Nacional y los colegios de San Bartolomé y el Rosario. ${ }^{57}$

El Congreso, debido seguramente a que muchos de sus miembros eran antiguos alumnos del Colegio, se resistió a la propuesta del Ejecutivo de incorporar del Colegio del Rosario en la Universidad, ${ }^{58}$ razón por la que la ley de mayo 21 de 1842 "que hace varios arreglos a la Universidad Central" únicamente incluyó al Colegio San Bartolomé y al Museo y Biblioteca Nacionales en la fusión a la Universidad Central. ${ }^{59}$

Entre tanto, una ley expedida el 10 de abril de 1842 reiteró en su artículo único que las cátedras de jurisprudencia y medicina de los colegios de San Bartolomé y del Rosario "han pertenecido y pertenecen a la Universidad Central", en virtud de que el artículo 20 de la ley 30 de mayo de 1835 había declarado la vigencia del Plan de enseñanza pública de 1826 en el que precisamente las cátedras de jurisprudencia de los colegios San Bartolomé y el

56 ALC 1842. Cámara de Representantes. Peticiones XII. Fol. 80. Es de anotar que es la única referencia que se tiene de este documento por lo cual, aunque se presume su propósito, esto es, que se reputasen universitarios los estudios de Jurisprudencia hechos en los colegios, se desconoce su alcance exacto.

57 Oficio No. 10. Bogotá, 16 de marzo, 1842, Mariano Ospina, Secretario del Estado en el Despacho del Interior y Relaciones Exteriores al Secretario de la Cámara de Representantes. ALC 1842. Cámara de Representantes. Tomo 353-XII. Peticiones. Fol. 80-81.

58 Memorial del Doctor Rafael Rivas al Juez Nacional de Cundinamarca. Bogotá, 12 de Febrero de 1859, en: Revista del Colegio Mayor de Nuestra Señora del Rosario Vol. XXIX. No. 287-288 (1934).

59 Ley 21 de mayo, 1842, artículo 1. 
Rosario habían sido incorporadas a la Universidad Central. ${ }^{60}$

Producida la negativa del Congreso a la incorporación del Colegio del Rosario a la Universidad Central, la Cámara Provincial de Bogotá, a cuyo cargo estaba el Colegio del Rosario, expidió una Ordenanza poniéndolo a disposición del Poder Ejecutivo para que este estableciera la Universidad en el edificio del Colegio cuando lo estimara conveniente. Es importante tener en cuenta los considerandos en que sustentó la Cámara Provincial tal determinación:

En primer lugar manifestó que la Cámara Provincial había sido requerida por el Poder Ejecutivo para proporcionar recursos con el fin de establecer la Universidad en la Capital, manifestándole que, a falta de cooperación por parte de esta, sería preciso trasladarla a alguna otra de las provincias del distrito universitario.

En segundo lugar, que la decadencia del Colegio sería inevitable debido a la incorporación a la Universidad de sus cátedras de jurisprudencia y medicina que había hecho el Plan General de Estudios, quedando reducido a una simple casa de educación, contra la voluntad explícita de sus fundadores y que, en tales circunstancias, debía buscarse el modo más adecuado y eficaz para que se cumpliera con aquella voluntad, medio que no podía ser otro que el de establecer la Universidad en el local del Colegio, destinando sus rentas a los mismos objetos de sus fundaciones. ${ }^{61}$

Entregado el Colegio a disposición del Poder Ejecutivo, este dispuso mediante el decreto del diez de diciembre de 1842 el establecimiento de las escuelas generales de Literatura y Filosofía y de Ciencias Físicas y Matemáticas de la Universidad del Primer Distrito en el edificio del Colegio del Rosario. Las de Medicina y Jurisprudencia en el de San Bartolomé y las de Ciencias Eclesiásticas en el Seminario. ${ }^{62}$ Igualmente dispuso que el Rector de la Universidad ejerciera las funciones anexas al rectorado del Colegio de San Bartolomé y que las funciones de Rector del Colegio del Rosario y de Primer Inspector de la Universidad se ejercieran por la misma persona.

60 Codificación Nacional. Tomo IX.

61 Cámara Provincial de Bogotá. Ordenanza No. 3 del 3 de Octubre, 1842 Dando reglas sobre el modo de establecer la Universidad Central en el Colegio del Rosario. Recopilación de las ordenanzas vigentes en la Provincia de Bogotá el 31 de Agosto, 1847 y de los Decretos de la Gobernación dados en su ejecución (Bogotá: impreso por Vicente Lozada, 1847), 11 y 12.

62 Decreto diciembre 10, 1842 "estableciendo las escuelas [sic] jenerales de la Universidad del Primer Distrito". G. de la N. G. No 591. Bogotá. domingo 18 de Diciembre, 1842. Trimestre 44. 
En lo que se refiere a los demás colegios provinciales, finalmente la ley de 8 de junio de 1844 extendió a estos y a los seminarios el permiso para que en ellos se adelantasen cursos universitarios destinados a la obtención de grados.

\section{Escuelas de Literatura y Filosofía y de Ciencias Físicas y Matemáticas}

En 1842, el Plan de Estudios impulsado por Mariano Ospina ${ }^{63}$ dividió el territorio de la República en tres distritos, en cada uno de los cuales habría una Universidad, designando a Bogotá como la capital del Primer Distrito Universitario. Reiteró lo dispuesto por el artículo 62 de la ley de 18 de marzo de 1826 en el sentido de que eran rentas de la Universidad, entre otras, las dotaciones de cátedras existentes en cualquiera de los seminarios o colegios, correspondientes a las facultades que solo podían enseñarse en las universidades.

El Estatuto Orgánico de la Instrucción Universitaria, ${ }^{64}$ del 20 de diciembre de 1844, reguló lo relativo a los colegios provinciales sujetos a régimen escolar universitario. Dispuso que en los que se establecieran cátedras de escuelas sujetas al régimen universitario hubiese un Rector cuyo nombramiento debía aprobar el poder ejecutivo y, cuando en los estatutos del respectivo colegio no se hubiera designado la autoridad que debía hacer el nombramiento, lo haría la Subdirección de Instrucción Pública de la Provincia.

Las escuelas universitarias establecidas en los colegios dependerían de la Universidad del respectivo Distrito y harían parte de ella, asuntos en los que reprodujo integralmente lo dispuesto anteriormente por la ley del 8 de julio de 1844, que contemplaba algunas reglas en relación con los colegios provinciales. Igualmente estableció las materias y el orden de enseñanza en la facultad de Jurisprudencia y dispuso la exigencia de contar con el grado de licenciado en Literatura y Filosofía como requisito para ser matriculado como cursante en las demás facultades mayores. Habría grados en todas las facultades de Bachiller, Licenciado y Doctor, excepto en Literatura y Filosofía en las que habría solo los dos primeros.

63 Decreto diciembre $1^{\circ}, 1842$ "que organiza las universidades". En Compilación de Normas sobre la Educación Superior ICFES (Bogotá: República Neogranadina, 1974), Vol. II, parte 2.

64 Decreto diciembre 20, 1844 “Orgánico de la instrucción universitaria”. Gaceta de la Nueva Granada, Bogotá, domingo 19 de enero de 1845 y en: Registro Oficial de los decretos y órdenes circulares del Poder Ejecutivo, año 1844: 149 a 190. 
Dos días después de la expedición del Decreto Orgánico se establecieron reglas de tránsito de sistema ${ }^{65}$ y el 24 de diciembre un nuevo decreto de organización de la Universidad del Primer Distrito dispuso que la Escuela de Literatura y Filosofía permanecería en el Colegio del Rosario y que la de Ciencias Físicas y Matemáticas se trasladaría al San Bartolomé, ${ }^{66}$ que además retenía la de Jurisprudencia. Se aclaró que la prohibición de establecer escuelas parciales de Jurisprudencia comprendía sólo a las Universidades y no a los colegios sujetos al régimen universitario, por lo cual en los demás colegios podrían crearse algunas cátedras de esta carrera. La Escuela de Ciencias Físicas y matemáticas retornó al Colegio del Rosario en 1848 por disposición del Presidente Tomás Cipriano de Mosquera, quien simultáneamente ordenó el traslado de la escuela de Literatura y Filosofía al Colegio de San Bartolomé. ${ }^{67}$

\section{Libertad de enseñanza}

El 8 de mayo de 1848 el Congreso decretó la libertad de enseñanza en todos los ramos. ${ }^{68}$ En consecuencia, los granadinos podrían recibir y adquirir la instrucción en establecimientos públicos o privados con el objeto de obtener grados académicos y, mientras el Poder Ejecutivo reglamentaba las universidades y colegios nacionales sobre las bases que estableciera la Ley, se observaría en estos respecto a la distribución, duración y materia de los cursos y exámenes, lo dispuesto en los estatutos universitarios de $1847 .{ }^{69}$

La Ley de Mayo 15 de 1850 reiteró la libertad de enseñanza en todos los ramos de las ciencias, las letras y las artes, agregando que en adelante el título científico no sería necesario para ejercer profesiones, por considerarlo una limitación a la libertad de trabajo y una forma de monopolio. Sin embargo, podrían obtenerlo quienes lo quisieran, previa presentación de un examen ante un Consejo de Profesores que habría en cada colegio, sistema por el cual el Colegio del Rosario confirió numerosos grados a partir de $1852 .{ }^{70}$

65 Decreto diciembre 22 de 1844 "que contiene disposiciones transitorias relativas al plan [sic] jeneral de instrucción pública". Registro Oficial de los Decretos y Órdenes Circulares del Poder Ejecutivo (1844): 190-191.

66 Decreto diciembre 24, 1844 "que arregla la Universidad del Primer Distrito". En Registro Oficial de los Decretos y Órdenes Circulares del Poder Ejecutivo, (1844): 191 y 192.

67 Decreto Ejecutivo de Junio 6, 1848. A.H.C.R. Vol. 35, Fol. 136-138

68 Ley de Mayo 8 de 1848, "Sobre libertad de enseñanza y habilitación de cursos".

69 Decreto ejecutivo de septiembre 14, 1847.

70 Los registros de estos exámenes y de los grados se encuentran en el AHCR Volúmenes 37 y 38 . Ver un ejemplo en Francisco Rengifo Ospina, "Un Grado en Bogotá a mediados del siglo XIX". En la Revista del Colegio Mayor de Nuestra Señora del Rosario Vol. XXIX. No. 287 y 288 (1934): 416 a 425. 
Se suprimieron las universidades. Las rentas y los edificios de los que disponían se aplicarían al establecimiento de colegios nacionales, los cuales se organizaron en ese mismo año. Habría tres en la República, uno en Bogotá, otro en Cartagena y otro en Popayán, los que se sostendrían con las rentas de las universidades suprimidas en los edificios que ocupaban aquellas. En cada uno de ellos se creó una Escuela de Jurisprudencia.

\section{Institucionalidad del Colegio del Rosario bajo el Régimen de Libertad de Enseñanza}

Decretada la libertad de enseñanza en 1850 por la ley 15 de mayo y suprimidas las universidades, se exceptuó al Colegio del Rosario de la norma que dispuso la destinación de los bienes y rentas de aquellas al establecimiento de colegios nacionales, al tiempo que se le devolvió el carácter de establecimiento provincial, que en adelante se regiría por las reglas que sobre edificio, bienes y rentas dictara la Cámara de Provincia. ${ }^{71}$

En ejercicio de las atribuciones dadas por la ley del 15 de mayo la Cámara Provincial de Bogotá restableció el Colegio del Rosario al estado que tenía antes de que se declararan universitarias las enseñanzas de facultades mayores, ordenó la aplicación de sus derechos, acciones y bienes a los objetos a los que desde el principio fueron destinados, al tiempo que declaró la vigencia de las Constituciones establecidas por el fundador en lo que no fueran contrarias al sistema de gobierno. Así mismo, restableció el régimen electivo de superiores y catedráticos por los alumnos internos mayores de 15 años. El ejercicio del patronato correspondería al Gobernador de la Provincia con las atribuciones de aprobar las elecciones de Rector, Vicerrector y catedráticos y la de remoción de los estos cuando graves motivos de utilidad pública o de conveniencia del establecimiento lo exigieran.

Por la primera vez la Cámara de Provincia nombraría al Rector, Vicerrector, Consiliario y Fiscal escogiéndolos entre los hijos del Colegio, quienes durarían en su cargo un año, pasado el cual se proveerían dichos cargos conforme lo dispusieran lo estatutos del Colegio. ${ }^{72}$

71 Ley Mayo 15, 1850, "Sobre Instrucción Pública".

72 Cámara Provincial de Bogotá. Ordenanza 104 Octubre 18 de 1850, "Reglamentando el Colegio de Nuestra Señora del Rosario" Ordenanzas dictadas por la Cámara provincial de Bogotá en las sesiones de 1850 (Bogotá: Imprenta Neogranadino, 1850). 
Rafael Rivas Mejía fue designado Rector e inmediatamente le solicitó al Congreso la emancipación del Colegio y que se le devolviera su ser individual e independiente del poder oficial.

El primero de marzo de 1853, por segunda vez, el Rector Juan Nepomuceno Núñez Conto y muchos de los ex alumnos del Rosario reclamaron del Senado y de la Cámara de Representantes un acto legislativo que declarara la independencia del Colegio del Rosario. ${ }^{73}$ Se tuvo conocimiento por parte de estos de que el Secretario de Estado en el Despacho de Gobierno había consignado en su informe a las Cámaras una consideración especial sobre el Colegio del Rosario, a la que acompañó un proyecto particular en el sentido de reconocerle su autonomía. El Congreso tramitó y expidió el Decreto Legislativo de 10 de marzo de 1853 "que declara independiente el Colegio del Rosario de Bogotá". Su artículo único reprodujo en parte el artículo primero de la ordenanza citada además de declararlo independiente de la Cámara Provincial de Bogotá.

\section{Expropiación para cárcel}

En medio de las circunstancias del alzamiento de Tomás Cipriano de Mosquera, Presidente del Estado del Cauca, contra el gobierno de Mariano Ospina Rodríguez, en 1860 el Intendente del Distrito Nacional de Cundinamarca decretó la expropiación del Colegio y lo convirtió en cárcel. El incidente fue contado años después por el Rector Francisco Eustaquio Álvarez al instaurar una demanda ante el Juez de Circuito de Bogotá contra el Gobierno de los Estados Unidos de Colombia reclamando el pago de 1033 pesos por concepto de arriendo durante diez meses y diez días que duró la ocupación del Colegio para destinarlo a cárcel. ${ }^{74}$

Relató el Rector que en 1860 el Poder Ejecutivo de la Confederación Granadina autorizó al Intendente Nacional de Cundinamarca para que decretase la expropiación del uso del edificio del Colegio para que sirviese de cárcel. El Intendente Pedro Gutiérrez Lee se dirigió al Rector Andrés María Pardo exigiéndole en arriendo el Colegio pero, ante la negativa del Rector, el mismo Intendente expidió el decreto de expropiación encargando de su

73 "Decreto independizando el [sic] colejio del Rosario de Bogotá". ALC 1853. Cámara de Representantes. Antecedentes de Leyes. Fol. 310 a 319 .

74 AHCR, Vol. 42, Fol. 77-78. Sostuvo el Rector en su escrito que la ocupación duró desde el 27 de septiembre de 1860 hasta el 5 de agosto de 1861 que, a razón de cien pesos mensuales, da la suma señalada arriba. 
ejecución al Prefecto del Departamento de Bogotá, quien lo llevó a cabo el 27 de septiembre de $1860 .^{75}$ Tal situación subsistió hasta el 3 de agosto de 1861, día en el que el General Mayor e Inspector General del Ejército comunicó al Rector Pardo que el edificio se hallaba desocupado. ${ }^{76}$

\section{El Colegio Militar}

Vencedor de la guerra civil de 1861, el General Tomás Cipriano de Mosquera estableció en los edificios de San Bartolomé y el Rosario un Colegio Militar y una Escuela Politécnica que se sostendrían, entre otros recursos, con las rentas y propiedades que pertenecían a estos colegios. ${ }^{77}$

Un mes más tarde el mismo Mosquera, como Presidente provisorio de los Estados Unidos de Colombia, expidió el decreto sobre desamortización de bienes de manos muertas, que adjudicó en propiedad a la Nación “Todas las propiedades rústicas y urbanas, derechos, acciones, capitales de censos, usufructos, servidumbres $\mathrm{u}$ otros bienes que tienen o administran como propietarios o que pertenecen a las corporaciones civiles o eclesiásticas y establecimientos de educación, beneficencia o caridad en el territorio de los Estados Unidos". ${ }^{78}$

La desamortización afectó al Colegio del Rosario por la redención en el Tesoro Nacional de algunos créditos de capitales cuyo pago estaba garantizado por censos constituidos sobre bienes que fueron objeto de desamortización, ${ }^{79}$ y por la inclusión de sus bienes en el ramo de desamortización, hasta que la ley 41 de 1864 exceptuó de la medida a los bienes, capitales y rentas de los establecimientos de educación, ${ }^{80}$ tiempo durante el cual los agentes nacionales de manos muertas percibieron los réditos y arriendos producidos por dichos bienes.

\footnotetext{
75 AHCR, Vol. 42. Fol. 77-78.

76 Cfr. AHCR, Vol. 44 fol. 30, expropiación de parte del edificio del C. R. Para utilizarlo como cárcel en 1861.

77 Decreto Agosto 24, 1861 “que crea un Colegio militar y una escuela politécnica”. Colombia, Leyes. Tomo IX, 328-330.

78 Decreto Septiembre 9 de 1861 "sobre desamortización de bienes de manos muertas". Colombia, Leyes. Tomo XIX, 398-402.

79 El Colegio del Rosario fue cobijado por el Decreto de septiembre 9, 1861, "sobre desamortización de bienes de manos muertas", en el Informe del [sic] Ajente Jeneral de Bienes Desamortizados e Inventario de los Mismos de 1872 aparecen como bienes que pertenecieron al Colegio y que fueron redimidos los siguientes: casa, carrera de Cartagena; Hacienda "Tilatá", Chocontá; casa, carrera de Majagual, números 15 y 17; casa, carrera de Tundama, número 51; Quinta de la Huerta de Jaime; Tierras, "Hato Viejo", Fómeque; casa, Plazuela de San Francisco; solares en Bogotá; tierras, Pensilvania, Tenjo; casa, carrera del Socorro, calle 1a.; tierras "Chinca”, Fómeque. Bogotá. Imprenta de Gaitán, s.f.

80 Ley 41 de mayo 29, 1864 "sobre bienes desamortizados", en: Codificación. Nacional. Tomo XXI. 1864.
} 
Aunque las instalaciones del Colegio fueron ocupadas para el establecimiento del colegio militar, en 1863 el Subdirector de turno, Mariano Moreno, informó al Secretario de la Corte Suprema Federal que únicamente se le había entregado hasta ese momento el edificio para la enseñanza, sin las dependencias de la biblioteca, la casa rectoral, el archivo, la sala de retratos, etcétera.

El mismo Subdirector informó en esa oportunidad que el colegio militar todavía no estaba en actividad porque ninguno de los candidatos reunía los requisitos legales para poder ingresar, tal como estaba previsto en el acto de su creación y, en consecuencia, por ahora se formaban los alumnos en un curso preparatorio encaminado a obtener dichos requisitos de ingreso al Colegio Militar. También informó en la misma comunicación que las Constituciones y reglamentos antiguos del Colegio le eran desconocidos y que "no rigen otras disposiciones que las que se sirve dar el ciudadano Jefe Municipal de quien, como Poder Ejecutivo en virtud de lo dispuesto, depende inmediatamente la enseñanza establecida en éste local." 81

\section{Recuperación de la Autonomía}

El tránsito hacia el restablecimiento de la autonomía del Colegio comenzó esta vez en la Asamblea Legislativa del Estado Soberano de Cundinamarca que, mediante una ley dictada en Zipaquirá el 11 de mayo de 1864, restableció el Colegio al estado legal que tenía el 18 de julio de 1861. Lo declaró independiente de la Asamblea Legislativa del Estado para que se rigiera por las Constituciones que le dejó el fundador en cuanto no fueran contrarias a la Constitución y a las leyes de la Unión y del Estado. La Asamblea del Estado elegiría esta vez entre los hijos del Colegio a un Rector y un Vicerrector mientras las elecciones se hacían conforme a las constituciones. El Patronato lo ejercería el Presidente del Estado Soberano de Cundinamarca.

El 6 de agosto de 1864 el Rector del Colegio informó a la Asamblea legislativa del Estado Soberano de Cundinamarca de los Estados Unidos de Colombia que en el Colegio del Rosario se habían iniciado los trabajos y establecido

81 Carta enviada por Don Mariano Moreno, Subdirector del Colegio del Rosario al señor Secretario de la Corte Suprema Federal. Agosto $1^{\circ}$ de 1863. Tomado del Juicio seguido por Don Juan N. Conto contra el Colegio del Rosario. AHCR, Vol. 42. Fol. 241. 
diez enseñanzas diversas, que la Consiliatura había abierto sus sesiones y que, una vez se arreglaran las rentas, se abriría el Colegio a los alumnos internos. ${ }^{82}$

El acta de la reunión de Consiliatura realizada el día anterior da cuenta de que no se habían encontrado en el archivo los libros ni quién diese razón de ellos. El Rector manifestó que no había recibido nada distinto a los edificios del Colegio, de los cuales la casa del Rector se encontraba en un estado de ruina completa,

Que sabía que no existían muebles de ninguna clase, ni una sola de las alhajas; que por informes privados que tenía del último Rector, señor Andrés Pardo, sabía que las llaves de la iglesia, la plata labrada [sic] i demás valores, estaban en poder del señor Presbitero N. Rodríguez, residente hoy en Venezuela, que fue Vicerrector i Capellán del Colegio.

Además informó que estaban abiertas para los alumnos externos once enseñanzas diversas y que los catedráticos que las daban las servían gratuitamente. Se acordó adicionalmente solicitarle al Gobierno de la Unión el reconocimiento a favor del Colegio de la renta que le correspondía por los censos redimidos en el Tesoro Nacional. ${ }^{83}$

Un año más tarde el Congreso de los Estados Unidos de Colombia expidió la ley $5^{\text {a }}$, de 18 de marzo de 1865, derogando la disposición que establecía el Colegio Militar y la Escuela Politécnica en los edificios del Rosario y San Bartolomé ${ }^{84}$ El Colegio del Rosario continuaría independiente como lo reconoció el decreto legislativo de 10 de marzo de 1853 y se regiría por las instituciones que estableció su fundador en cuanto fueran compatibles con la legislación nacional. En la misma fecha se expidió la ley $6^{\mathrm{a}}$ indemnizando al Colegio del Rosario. ${ }^{85}$

La Sindicatura aceptó la cesión del Laboratorio químico nacional, que estaba a cargo de Ezequiel Uricoechea, en compensación por las deudas cuyo pago reclamó en igual sentido el Rector del Colegio. ${ }^{86}$

82 Carta enviada por la Presidencia de la Asamblea Legislativa del Estado Soberano de Cundinamarca de los Estados Unidos de Colombia al Rector del Colegio de N. S. del Rosario. Agosto 6 de 1864. AHCR Vol. 42. Fol. 292.

83 AHCR Vol. 130. Fols. 72-74.

84 El proyecto del Decreto puede consultarse en el AHCR Vol. 43. Fol. 239.

85 Ley $6^{\circ}$ del 10 de marzo de 1953.

86 Carta enviada al Rector por Don Antonio del Real, Secretario del Interior y Relaciones Exteriores. AHCR Vol. 43. Fol. 209. 
Reconocida su autonomía se reinstauraron en el Colegio los estudios de Jurisprudencia, regidos por las normas establecidas en el Código de Instrucción Pública de 1858 cuya vigencia había sido declarada expresamente a comienzos del año. ${ }^{87}$ En el mismo año de 1865 se informó sobre las cátedras que se dictaban en el Colegio, entre las cuales se mencionan las de derecho civil, procedimientos judiciales, legislación civil y economía política. ${ }^{88}$

El 28 de octubre de 1865 se le comunicó al Rector una resolución referida al ejercicio del patronato sobre el Colegio por parte del Presidente Nacional. Sin embargo dicha resolución fue revocada por el propio Poder Ejecutivo Nacional el 14 de diciembre de 1865 debido a que la soberanía del Estado de Cundinamarca, en cuyo territorio se hallaba el Colegio, no había sido delegada al Gobierno general de manera clara y expresa sobre el particular y, por lo tanto, correspondía ejercerla "en su plenitud" en relación con estos asuntos a las autoridades respectivas de dicho Estado ${ }^{89} \mathrm{y}$, en consecuencia, el Patronato del colegio fue ejercido durante los siguientes años por el Gobierno del Estado Soberano de Cundinamarca. ${ }^{90}$

\section{Guerra Civil y Polarización}

En 1876 estalló la "guerra de las escuelas", una de cuyas causas principales fue la disputa por el tipo de enseñanza impartido en las escuelas de la Universidad Nacional, atacada por los antirradicales como inmoral, contraria a los fines del Estado y a los intereses de la sociedad. Se trató de una guerra contra las enseñanzas y la universidad liberales en la que los estudiantes participaron activamente en la contienda militar, muchos de los cuales se vincularon a las filas radicales..$^{91}$

Durante la guerra civil de 1876 se cerraron los colegios y la mayoría de estudiantes, que eran de filiación liberal ya que los conservadores no enviaban sus hijos al San Bartolomé ni al Rosario debido a la militancia política generada por la búsqueda del control de los dos institutos, tomaron

87 Ley Febrero 9, 1865.

88 Informes sobre los alumnos que hay en el Colegio, las materias que se dictan y los nombres de los catedráticos. AHCR, Volumen 43. Folios 286-287.

89 Poder Ejecutivo Nacional. Secretaría de lo Interior y Relaciones Exteriores. Carta de Santiago Pérez al Rector del Colegio del Rosario. Diciembre 14, 1865. AHCR Vol. 43. Fol. 227.

90 Acerca del ejercicio del Patronato en 1870 por parte del Gobierno del Estado. AHCR Vol. 129. Fol. 167.

91 Carol Ardila Villamil, Aproximación histórica a la Facultad de Derecho, Ciencias Políticas y Sociales de la Universidad Nacional de Colombia (Bogotá: 2001), 35. 
las armas en favor del Gobierno del Presidente Aquileo Parra. Algunos catedráticos hicieron lo propio, entre los que se destacó el doctor Ángel María Galán al mando del Batallón $5^{\circ}$ de Bogotá. ${ }^{92}$

Debido a la situación del país la Consiliatura autorizó al Rector para suspender las tareas escolares. ${ }^{93}$ En el Colegio se acuartelaron los batallones de la Guardia Colombiana ${ }^{94}$ con cuya ocupación las instalaciones del Colegio quedaron en muy mal estado.

Finalizada la guerra, previa solicitud del Rector Gil Colunje, el Poder Ejecutivo ordenó el 15 de junio de 1877 la devolución del edificio y posteriormente asumió algunos de los gastos de su reparación.

El 29 de noviembre de 1879 la Asamblea Legislativa del Estado Soberano de Cundinamarca expidió la Ley $6^{a}$, donde reformó las Constituciones de Colegio de Nuestra Señora del Rosario, en la cual dispuso que el Rector y el Vicerrector serían de libre nombramiento y remoción del Gobernador del Estado y que, en ejercicio del Patronato, ejercería su suprema inspección, dictando para tal efecto los reglamentos necesarios para su régimen y disciplina, correspondiéndole velar por el cumplimiento de la voluntad del fundador así como concurrir a las deliberaciones y decisiones de la Consiliatura. Al Ministro de Cuentas del Estado se le atribuyó el examen y fenecimiento de las cuentas del Colegio. Finalmente, se nombró Rector a Januario Salgar en reemplazo de Gil Colunje.

El mismo Colunje, junto con Francisco Eustaquio Álvarez, le solicitaron a la Corte Suprema Federal la suspensión de la Ley $6^{a}$ del Estado Soberano de Cundinamarca, que consideraban violatoria de la Ley $5^{\mathrm{a}}$ nacional de $1865,{ }^{95}$ expedida por el Congreso de los Estados Unidos de Colombia que, como quedó anotado, declaró que el Colegio del Rosario continuaría independiente en los términos del Decreto Legislativo del 10 de marzo de 1853 y que se regiría por las "Instituciones" establecidas por su fundador en cuanto fueran compatibles con la legislación nacional.

\footnotetext{
92 Luis María Mora, Croniquillas de mi ciudad (Bogotá: Banco Popular, 1972), 21. Tulio A. Forero, "En el aniversario de la gran batalla de Garrapata" en: El Espectador, Noviembre 20, 1927. Citados por: Patricia Álvarez Rosas, "Ley de Honores al Colegio del Rosario", en: Revista del Colegio Mayor de Nuestra Señora del Rosario No.557 (1992): 51 a 57.

93 AHCR, Miscelánea, Volumen 59, Folio 110.

94 AGN Sección República, Secretaría de Guerra y Marina, Tomo 1022, Folio 587.

95 Diario Oficial No. 4616 del 20 de enero de 1880,7511-7512.
} 
Debido a que la Constitución exigía unanimidad de los votos de los Magistrados para suspender los efectos de los Actos Legislativos de los Estados, la solicitud de suspensión resultó negada como consecuencia de una decisión dividida de la Corte, cuyo proyecto de fallo, elaborado por el Magistrado José M. Rojas Garrido y secundado por el Magistrado Rafael Martínez R., consideró que la Ley del Estado acusada no disponía que el Colegio dejara de ser independiente ni de regirse por las Instituciones del fundador, por lo que ninguna de sus disposiciones, en su sentido literal, prevenía expresamente lo contrario de la Ley Nacional. Agregó que a pesar de su nominación, en la que aparece que se reforman las Constituciones, en ninguno de los artículos de la ley acusada se expresó en qué consistía dicha reforma,

\section{[...] por el contrario, en el inciso $2^{\circ}$ de la lei [sic] acusada, se impone al Gobernador, en ejercicio del Patronato de dicho Colejio [sic] el deber de hacer hasta donde fuere posible, que se cumpla la voluntad del fundador espresada en las constituciones, lo cual está de acuerdo con el precepto de la lei [sic] nacional citada.}

Sostuvo la ponencia que el solo hecho de que la ley $5^{\text {a }}$ dispusiese que el Colegio del Rosario continuara independiente y que se rigiese conforme a las Instituciones que le legó su fundador no implicaba, por lo menos con claridad, precepto alguno de que el Estado perdiese el derecho de legislar que había ejercido sobre dicho Colegio, ni tampoco la declaratoria de que este en lo sucesivo hubiese de ser asunto del Gobierno nacional y que por lo tanto no podía negarse que el Estado de Cundinamarca se había creído con el derecho de soberanía para legislar sobre el régimen del Colegio, derecho reconocido expresamente por el Gobierno general de la Unión.

Se apartaron de la decisión los Magistrados Manuel Ezequiel Corrales y Juan Agustín Uricoechea. ${ }^{96}$

Posteriormente la misma Ley $6^{\text {a }}$ del 29 de noviembre de 1879, "por la cual se reformaban las Constituciones del Colegio del Rosario", expedida por la legislatura del Estado Soberano de Cundinamarca, fue sometida al análisis del Senado de Plenipotenciarios de conformidad con lo permitido por la Constitución de 1863, cuerpo que tenía la competencia para fallar

96 Diario Oficial No. 4616 del 20 de enero, 1880, 7511-7512. 
"definitivamente y de modo inapelable" sobre la validez de los actos legislativos de los Estados.

La Resolución del Senado de plenipotenciarios, adoptada en sus sesiones del 7 y 14 de Mayo de 1880, determinó que la normatividad aplicable al Colegio del Rosario era la contenida en la ley $5^{a}$ nacional del 18 de Marzo de 1865, y que la Ley $6^{a}$ del Estado Soberano de Cundinamarca era contraria al inciso $5^{\text {a }}$ del Artículo 17 de la Constitución Nacional pues, de acuerdo con este, correspondía al Gobierno de la Unión la competencia legislativa en lo relativo a los establecimientos nacionales. ${ }^{97}$

La decisión del Senado de Plenipotenciarios fue comunicada al Colegio, luego de lo cual la Consiliatura declaró que era del caso que el señor Gil Colunje reasumiera el rectorado, pues lo era cuando se expidió la ley anulada. $^{98}$

El 29 de mayo de 1880 la Secretaría de Instrucción Pública expidió una Resolución "por la cual se declara que el Patronato del Colegio de Nuestra Señora del Rosario corresponde al Presidente de la República, así como la facultad de nombrar Rector y Vicerrector interinos" en cuyos considerandos se hizo una extensa relación de la normatividad reguladora de la institución con los poderes públicos desde su fundación. En desarrollo de la referida disposición, el Presidente Núñez nombró el 9 de junio de 1880 a Manuel Ezequiel Corrales e Ignacio Londoño como Rector y Vicerrector interinos del Colegio. ${ }^{99}$

A su turno, el Decreto 745 del 31 de agosto de 1880 había declarado válidos para la obtención de grados universitarios los cursos que se hubiesen ganado o que se ganasen en adelante por los alumnos de la Universidad Nacional en el Colegio Mayor de Nuestra Señora del Rosario. ${ }^{100}$

Tres meses después, el Congreso de los Estados Unidos de Colombia expidió la ley 106 de 1880, ${ }^{101}$ en la que determinó que era potestad del Poder Ejecutivo

\footnotetext{
97 Ver informe de la Presidencia del Consejo Académico al Secretario de Instrucción Pública, fechado el 10 de julio, 1881. Diario Oficial No. 5088 del lunes 1 de agosto, 1881.

98 Acta de Consiliatura, sesión de 20 de mayo de 1880. AHCR. Caja 62. Folios 153-156.

99 Decreto No. 434 de junio 9, 1880. Diario Oficial No. 4739 del 14 de junio, 1880, 8004

100 Diario Oficial No. 4801 de septiembre 6, 1880.

101 Ley 106 de agosto 23, 1880. Diario Oficial No. 4794 del 29 de agosto, 1880.
} 
la organización de la enseñanza pública oficial en todos sus ramos y que le correspondía nombrar los superiores, catedráticos y demás empleados de la Instrucción Pública Nacional.

El 4 de septiembre fijó los sueldos de los empleados del Colegio ${ }^{102}$ y el 6 de septiembre de 1880, con fundamento en las facultades de la ley 106, el Presidente Rafael Núñez expidió el Decreto 771 "que organiza provisionalmente el Colegio de Nuestra Señora del Rosario", ${ }^{103}$ que en su parte motiva refería expresamente al "espíritu de las Constituciones primitivas del Colegio Mayor de Nuestra Señora del Rosario" como fundamento de las decisiones que en su contenido se adoptarían.

El Decreto referido dispuso, en primer lugar, que el Colegio continuara siendo independiente de la Universidad Nacional y que se rigiese por las "instituciones" fundamentales que estableció, con la aprobación del Gobierno de la época, el Arzobispo Don Cristóbal de Torres, pero sólo en aquellas disposiciones que fuesen compatibles con la legislación nacional. El mismo Decreto confió la dirección de la enseñanza impartida por el Colegio al Poder Ejecutivo Federal al cual le atribuyó también la facultad de nombramiento de sus superiores y empleados, los cuales durarían en funciones por todo el tiempo de su buen desempeño, a juicio del Poder Ejecutivo de la Unión. ${ }^{104}$

El resto del articulado del Decreto se dedicó a las funciones de la Junta de Inspección y Gobierno, que se compondría del Rector, el Vicerrector, del Inspector y de los pasantes, a las funciones del Rector, quien presentaría anualmente al Poder Ejecutivo Federal, en su calidad de Patrono, un informe sobre la marcha del Colegio, sus rentas, exámenes y certámenes y, finalmente, el Decreto regulaba las funciones del Vicerrector, el Inspector y Pasantes, del Secretario, del Síndico y agregaba algunas "Disposiciones generales" en las cuales se señaló, entre otras cosas, la asignación económica de los catedráticos. ${ }^{105}$

Seis meses después, el Decreto 167 del 7 de marzo de $1881^{106}$ estableció las "“bases generales para la enseñanza nacional universitaria”. Este decreto,

102 Decreto No. 7864 de septiembre, 1880. Diario Oficial No. 4804, 9 de septiembre de 1880, 8263.

103 Decreto No. 771 de 6 septiembre, 1880, "que organiza provisionalmente el Colegio de Nuestra Señora del Rosario".

104 Decreto No. 771 de 1880 , artículos $2^{\circ}$ y $3^{\circ}$

105 Decreto No. 771 de 1880 , artículos $4^{\circ}$ a $20^{\circ}$.

106 Decreto No. 167 de marzo 7, 1881. Diario Oficial No. 4961 de marzo 7, 1881. 
que se basó también en las atribuciones de la ley 106, reiteró en su artículo cuarto que, de acuerdo con el artículo segundo del decreto 771 del 6 de septiembre de 1880, la dirección del Colegio del Rosario correspondía al Poder Ejecutivo Federal.

Conforme al artículo 31, las disposiciones del decreto y las que para su desarrollo dictara el Consejo Académico (órgano encargado de la administración y régimen interior de la Universidad Nacional ${ }^{107}$ regirían en el Colegio del Rosario sin perjuicio de lo que dispusieran sus constituciones particulares en la parte de ellas que la Ley había declarado vigente. ${ }^{108}$

El 10 de julio de 1881 el Secretario de Instrucción Pública dirigió una nota al Consejo Académico en la que sometió a su estudio, entre otros asuntos, el relativo al alcance del referido artículo 31 que implicaba la delimitación entre las competencias del Ejecutivo y aquellas propias del Colegio. En su consulta, el Secretario de Instrucción Pública planteaba que a su entender les correspondía al Ejecutivo y al Consejo Académico la parte puramente docente del Colegio del Rosario. ${ }^{109}$

En su respuesta el Consejo señaló que por la naturaleza particular de su origen institucional y por su estrecha relación con la causa pública estaba sujeto, por así decirlo, a dos modos de legalidad: una legalidad que denominó civil, "por cuanto el Colegio es persona jurídica y tiene reglas propias de administración que provienen de su fundación misma", y una legalidad política o constitucional, proveniente de la relación que tiene el establecimiento con la autoridad del Gobierno Cundinamarqués y con el Gobierno general.

En lo referente a la legalidad civil, para el Consejo era evidente que una parte muy considerable de las constituciones del Colegio había caído en desuso al ser incompatible con las instituciones republicanas y las costumbres democráticas que con ellas se habían desarrollado. Sin embargo, en todo lo que no ofreciesen motivo de incompatibilidad, aquellas constituciones debían ser

107 Sus funciones, organización, competencia y calidades, en el Capítulo III del Decreto. Artículos 11 a 19

108 Mediante el Decreto No. 36, 25 de enero, 1881 "por el cual se hacen nombramientos de catedráticos de Economía Política, derecho civil español, procedimientos judiciales y derecho internacional en el Colegio del Rosario”. Diario Oficial No. 4929, 28 de enero, 1881, 8763. El decreto 75 de febrero 1 de 1881 fijó la duración de los empleados del Colegio. Diario Oficial 4938 de 8 febrero, 1881,8799 .

109 Nota No. 697 de la Sección Primera de la Secretaría de Instrucción Pública, fechada el 29 de marzo de 1881, citada en el informe del Consejo Académico al Secretario de Instrucción Pública, fechado el 10 de julio, 1881. Diario Oficial No. 5088 de $1^{\circ}$ agosto, 1881. 
religiosamente cumplidas, tanto por respeto a un principio moral como por respeto a las leyes civiles que garantizaban la fuerza permanente de la voluntad del fundador, garantía que, en últimas, sostuvo el Consejo, lo era del derecho de propiedad ejercido por ese mismo fundador.

Sin embargo, el Consejo sostuvo que no le incumbía decidir acerca de cuáles de las disposiciones del fundador podían y debían seguir observándose y cuáles no, pues esto era asunto de la competencia de los "legítimos administradores del colegio".

Por lo que hace a la legalidad constitucional o politica, está determinada por actos claros y sencillos; a tal punto que ya no hay necesidad ni de remontarse al examen de la ley nacional de 10 de marzo de 1853, ni menos al Decreto de 24 de agosto de 1861, expedido por el Gobierno Provincial.

Recordó en cambio que la Resolución adoptada por el Senado de Plenipotenciarios en relación con la ley $6^{\text {a }}$ de Cundinamarca de 29 de Noviembre de 1879, que reformaba las Constituciones del Colegio de Nuestra Señora del Rosario, había fijado la jurisprudencia que debía regir al Colegio. Dicha Resolución del Senado de Plenipotenciarios, calificada por el Consejo como "soberana", dispuso que el Colegio Mayor de Nuestra Señora del Rosario estaba sometido a la ley $5^{a}$ nacional del 18 de marzo de 1865, la cual ordenó que el Colegio continuara independiente, tal como lo había reconocido el Decreto legislativo de 10 de marzo de 1853 y que se rigiese conforme a las instituciones del fundador en cuanto fuesen compatibles con la legislación nacional, derogando de paso el Decreto de 24 de agosto de 1861, que había dispuesto lo contrario.

Por tanto es incuestionable que el Colegio Mayor de Nuestra Señora del Rosario no puede ser sometido a reglas que no sean las prescritas por las instituciones del fundador, para mantenerlo en independencia, y las que estableció la ley de 10 de marzo de 1850, reproducida en cierto modo por el 18 de marzo de 1865.

Sin embargo, existía una parte menos pacífica de la resolución del Senado de Plenipotenciarios en la que calificó también de inconstitucional la ley cundinamarquesa de 1879 , aduciendo que era contraria al inciso $5^{\circ}$ 
del artículo 17 de la Constitución pues, conforme con este correspondía al Gobierno de la Unión regular lo concerniente a los "establecimientos nacionales".

Manifestó el Consejo Académico que no comprendía la aplicación de esta parte de la resolución del Senado de Plenipotenciarios que parece haber tenido por objeto calificar indirectamente de "establecimiento nacional" al Colegio del Rosario, pues ello se hallaría en clara contradicción con la proposición senatorial que precisamente declaró violada la ley nacional de 1865 y que confirmó la independencia del Colegio así como la vigencia exclusiva de sus Instituciones. Para el Consejo Académico era claro que siendo "independiente", el Colegio no era un "establecimiento nacional" y, por lo tanto, no estaba sujeto a la legislación ni a la autoridad del Gobierno general.

Para el Consejo Académico la cuestión del patronato era de otro orden: que lo ejerciese el Presidente de la República, el Gobernador de Cundinamarca o el Arzobispo de Bogotá, era "asunto de disciplina", no de "jurisprudencia" del Colegio, por lo que no tenía el Consejo necesidad de emitir concepto acerca de este punto y debía limitarse a considerar si eran aplicables al Colegio las disposiciones universitarias.

Consideraba el Consejo que desde luego eran inadmisibles en lo referente a lo económico y administrativo, porque las disposiciones universitarias establecían numerosas enseñanzas de Literatura y Filosofía y de Jurisprudencia, que eran de imposible adopción por el Colegio del Rosario debido a lo exiguo de sus rentas, recursos y local. Agregó que:

\footnotetext{
Por otra parte, aún sin dar efecto retroactivo, respecto del año en curso, a las disposiciones universitarias relativas a matrículas, al número y orden de los recursos y a la prohibición muy racional de habilitar algunos, es evidente que la situación y disciplina de aquel Colegio no se acomoda a las justas exigencias de la disciplina universitaria establecida por el Decreto de 7 de marzo último.
}

Añadió el Consejo en su concepto que la unión de los colegios del Rosario y San Bartolomé establecida por reglas comunes sobre enseñanzas y cursos de la Universidad, era imposible, pues los elementos y la disciplina interna 
de los dos establecimientos diferían notablemente y, de tal unión, "en cierto modo artificial", solo resultarían perjuicios para la Universidad y para el Colegio del Rosario."

\title{
10. Convención de los hijos del Colegio
}

Ante las razones de orden económico que se oponían a una administración directa del Colegio por parte del Poder Ejecutivo y del Consejo Académico, para este último estaba demostrado que la independencia del establecimiento era condición necesaria de la legalidad de su existencia, por lo que recomendó que se buscase en las Constituciones legadas por el fundador, el medio para sacar al Colegio de la situación anómala en que se hallaba y de "ponerlo en camino de reconstruir su administración y de regenerarse por su gobierno propio y su buena economía."

\begin{abstract}
El medio que halla el Consejo es el que sugieren las mismas Constituciones del Colegio, conforme a las cuales, en caso muy graves que ocurran sobre gobierno del establecimiento, puede convocarse una convención de todos sus hijos que tenga legítimamente este carácter, a fin de que tal cuerpo, como legítimo representante también del fundador, estatuya lo conveniente. Adoptándose este camino, podrá reconstituirse el Colegio conforme a sus Constituciones y su conveniencia, devolviéndose la autonomía que le reconoció por las leyes de 1850 y 1865 y por la resolución Senatorial de 1880.
\end{abstract}

La convocatoria a la Convención debía realizarla el Poder Ejecutivo, en su calidad de Patrono del Colegio, que también la presidiría por medio del Secretario de Instrucción Pública. A ella concurrirían, de acuerdo con las Constituciones, los hijos del Colegio, tanto ausentes como presentes en Bogotá, pudiendo hacerlo los primeros por medio de apoderados. El Secretario de Instrucción Pública o un delegado del Patrono certificaría previamente los títulos de todos aquellos que se presentasen como "Hijos del Colegio" reclamando el derecho de concurrir a la convención y la calificación se haría conforme a lo dispuesto en las "republicanas constituciones que dictó el fundador". La convocatoria debería hacerse a la mayor brevedad posible a fin de que los convocados pudieran asistir a la convención durante el mes de octubre de 1881. 
En caso de aceptar el Poder Ejecutivo este medio, el Consejo se reservaría indicarle oportunamente las partes de las constituciones que en su concepto habrian de quedar vigentes, para que el Gobierno, en uso del Patronato, lo declare así a la Convención.

En conclusión, el Consejo Académico consideró que el Poder Ejecutivo debía devolverle la independencia y autonomía al Colegio del Rosario y que para llevar a cabo este propósito, sin dejar el establecimiento en una situación anómala y peligrosa, urgía convocar la convención y asignarle a ella la autoridad sobre el Colegio en lo referente al gobierno y administración, con el propósito de que dispusiese lo que estimase conveniente de acuerdo con las constituciones. ${ }^{110}$

Como consecuencia del anterior informe del Consejo Académico, calificado por el Presidente de los Estados Unidos de Colombia como "extenso y bien meditado" y tendiente a buscar

[...] la más justa y conveniente entre las organizaciones a que pueda quedar sujeto el antiguo Colegio de Nuestra Señora del Rosario, a fin de que en él se concilien las diversas formas del propósito que animó a su ilustre fundador y que han abrigado todos los Gobiernos de la República de hacer de dicho plantel un foco de ilustración y de moralidad para la enseñanza de la Juventud

Se dictó el Decreto 543 del 29 de julio de $1881^{111}$ en el cual el Ejecutivo acogió la solución propuesta por el Consejo, plenamente convencido de que la misma era "la que puede asegurar mejor tan importante resultado".

El Decreto convocó a la Convención a todos los hijos del Colegio del Rosario quienes, de conformidad con las constituciones de este tenían "las facultades de examen y reforma de dichas Constituciones". Dicha convención debía reunirse en Bogotá el 20 de octubre siguiente; podrían asistir a ella los hijos del Rosario que calificara y reconociera como tales una comisión nombrada en el mismo Decreto.

110 Secretaría de Instrucción Pública. Colegio Mayor de Nuestra Señora del Rosario. Informe del Consejo Académico. Julio 10 de 1881. Diario Oficial No. 5088 de $1^{\circ}$ de agosto, 1881, 9494-9505.

111 Decreto No. 543 de julio 29 de 1881 . Diario Oficial No. 5088 de $1^{\circ}$ agosto, 1881. El Decreto tiene la firma del Presidente Núñez y del Secretario de Instrucción pública, Ricardo Becerra. La idea del ejecutivo fue que la reorganización del colegio fuera definitiva y "se elaborase y llevase a cabo preferentemente en su parte sustancial, esto es, en la concordancia de sus antiguas instituciones con las actuales de la República y con el espíritu de nuestra sociedad, sin perjuicio de respetar en cuanto es posible las tradiciones de dicho Colegio". Resolución de la Secretaría de Instrucción Pública. Bogotá, 8 de noviembre, 1881. Diario Oficial No. 5181-5182, del 10 de noviembre, 1881 . 
Como miembros de la comisión fueron designados Luis María Cuervo y Juan Agustín Uricoechea, quienes debían ejercer sus funciones bajo la presidencia del Secretario de Instrucción Pública, quien tenía voz y voto en las determinaciones de esta. Un mes después ${ }^{112}$ Cuervo y Uricoechea remitieron al Secretario de Instrucción Pública un oficio en el que señalaban que, en cumplimiento de la comisión conferida, enviaban la lista de los hijos del Rosario, para cuya confección el Rector del Colegio había puesto a su disposición el archivo de este, del cual habían tomado la mayoría de los nombres; los demás los había incluido en la lista por su propio conocimiento, aunque no hubieran aparecido los respectivos expedientes.

Un informe preparado por el Consejo Académico relativo a la parte vigente de las Constituciones del Colegio le fue enviado al Secretario de Instrucción Pública, a modo de indicaciones que podían servirle para señalar a la Convención de los hijos del Colegio los puntos a los que debían ceñirse sus deliberaciones. ${ }^{113}$

Para elaborar el informe el Presidente del Consejo nombró como comisionado a Luis M. Cuervo quien, luego de estudiar las Constituciones del Colegio y los documentos relativos a su fundación se dirigió al Secretario de Instrucción Pública manifestándole lo que según su parecer debía plantearle a la Convención. Eran seis puntos los que a su juicio constituían la base esencial de la reorganización del Colegio y sobre los cuales debía prestar su atención a la hora de legislar. Tales puntos según Cuervo conciliaban debidamente la índole de las Constituciones del Colegio con el carácter de las instituciones públicas.

El primer punto, referente al Patrono, recomendaba que teniendo en cuenta que el Rey de España había ejercido el patronato del Colegio desde el 12 de junio de 1664, la Convención debiera declarar y reconocer como Patrono del Colegio al Poder Ejecutivo Nacional.

Las "elecciones" de Rector y Vicerrector del Colegio debían llevarse a cabo conforme lo disponían las Constituciones, es decir, que todos los hijos del

112 Oficio de los comisionados que fueron a sacar la lista de los hijos del colegio del Rosario, dirigido al Secretario de Instrucción pública. Bogotá, agosto 29, 1881. Diario Oficial No. 5119 de 3 de septiembre, 1881. Se publicó también en el Diario Oficial No. 5121 de 6 de septiembre, 1881.

113 Secretaría de Instrucción Pública. Expediente No. 1761. Bogotá, 24 de septiembre, 1881. En AGN, Sección República, Secretaría de Instrucción Pública, Tomo IX, 188 y ss. 
Colegio residentes en Bogotá votaran en el día que se determinase mediante una papeleta, primero por tres individuos para Rector y enseguida por otros tres para Vicerrector, debiendo recibirse los votos en la Secretaría del Colegio de la manera que lo reglamentase la convención.

Concluida la hora fijada para la votación, debían reunirse el Vicerrector, un Consiliario nombrado por la Junta de Consiliarios, un hijo del Colegio nombrado por el Patrono y el Secretario del Colegio, quienes una vez verificado el escrutinio pasarían al poder ejecutivo el resultado, para que este, entre los tres con mayor número de votos, nombrara tanto al Rector como al Vicerrector, "teniendo en cuenta que el escrutinio deberá hacerse separadamente, para que pueda hacerse de igual modo la elección".

La elección de consiliarios se efectuaría de la misma manera, pero sin la intervención del Poder Ejecutivo, ya que el nombramiento de consiliarios "pertenece únicamente a los hijos del colegio [...] y al efecto la Junta que haga el escrutinio lo comunicará directamente a los favorecidos".

En relación con los consiliarios, señalaba Cuervo que esta Junta, con las atribuciones que la Convención le señalará, debía estar compuesta por cinco hijos del Colegio: tres nombrados popularmente por los hijos del Colegio, uno por el Patrono y el quinto por el Rector. Podría formar parte el Rector pero en este caso no tendría derecho a nombrar Consiliario. El Vicerrector tendría voz pero no voto en la Consiliatura.

El cuarto punto del informe de Cuervo se refería a los catedráticos, quienes serían nombrados por el patrono al escoger uno de cada terna que para cada clase le presentase la Junta de consiliarios. Los Catedráticos debían ser hijos del Colegio. El quinto, que le mereció un detallado informe, lo dedicó a la religión.

El sexto y último punto del informe de Cuervo se refería a la recepción de Colegiales, tema respecto al cual indicaba que la mayor parte de las disposiciones de las constituciones habían caído en desuso por lo que solo debía conservarse el juramento de fidelidad y amor al Colegio y respecto de condiciones personales, certificados respetables de la buena conducta del aspirante y de no padecer enfermedad contagiosa habitual. Finalizaba 
Cuervo señalando que en lo demás relativo a las formalidades, debían quedar vigentes las constituciones del Colegio.

\section{La Convención.}

La convención se reunió en Bogotá durante los días cuatro y seis de noviembre de 1881. Dispuso que una Comisión compuesta por cinco hijos del Colegio nombrados por el Secretario de Instrucción Pública Nacional se ocupase de elaborar un proyecto de reorganización interior y fundamental del Colegio, proyecto que debía atender tanto la voluntad del fundador, como la concordancia de esta con las instituciones de la República, sin perjuicio del respeto a las tradiciones del Colegio. Este proyecto debía ser sometido para su examen y aprobación definitiva a la Convención de hijos del Rosario que para tal efecto debía reunirse el 20 de enero siguiente, según su propia determinación.

La comisión nombrada por el Secretario de Instrucción Pública estuvo integrada por el doctor Agustín Núñez, los señores Luis M. Cuervo, Pedro Navas Azuero, José Segundo Peña y Constancio Franco. El Secretario de Instrucción Pública solicitó encarecidamente a la Comisión que procediera cuanto antes a desempeñar su cometido, de modo que sus trabajos pudieran someterse a consideración de la convención de hijos del Colegio el día previsto. ${ }^{114}$

El 22 de diciembre de 1881 la Comisión dio el segundo y último debate al proyecto reformatorio de las Constituciones, el cual le fue enviado al Secretario de Instrucción Pública el 16 de enero de 1882 con el nombre de Proyecto "que reorganiza el Colegio de Nuestra Señora del Rosario"115

Rafael Núñez como Presidente y su Secretario de Instrucción Pública, Carlos Sáenz E. expidieron el Decreto 69 de $1882^{116}$ mediante el cual se nombró al Doctor Manuel Ancízar Rector en propiedad del Colegio del Rosario. ${ }^{117}$

114 Resolución de la Secretaría de Instrucción Pública, Bogotá, 8 de noviembre, 1881. Diario Oficial No. $5181-5182$ del 10 de noviembre, 1881.

115 El Diario Oficial No. 5255 de enero 25, 1882, 10071, contiene el texto íntegro del proyecto.

116 Decreto No. 69, 6 de febrero 1882, "por el cual se nombra Rector del Colegio del Rosario". Diario Oficial No. 5272 del 13 de febrero, 1882, 10139 .

117 Ancízar había nacido en Santafé en 1812, obtenido el grado de doctor en jurisprudencia y el título de abogado en la Universidad de Cuba. 
A los pocos días del nombramiento de Ancízar, el Presidente Núñez dictó un nuevo decreto destinado a "reorganizar" el régimen del Colegio, "sobre las bases de las Constituciones del Fundador"118 en el cual creó una Junta Provisoria formada por hijos del Colegio, compuesta de diez a quince miembros cuya función consistiría en admitir los colegiales. La junta debía cesar en sus funciones una vez que hubiese diez colegiales en ejercicio.

Además de la Junta, el Presidente Núñez nombró como Consiliarios a los Señores Benigno Guarnizo, Gonzalo Currea y Florentino Vezga, pues en ese momento no existía en el Colegio Cuerpo electoral constitucional que hiciera los nombramientos. Como soporte para su actuación invocó su calidad de Patrono, conforme a la cual y según las Constituciones, le correspondía "proveer lo conveniente en todo caso extraordinario". ${ }^{119}$

El decreto determinó también los cursos que se dictarían en el Colegio: lengua castellana, aritmética, contabilidad y cálculo, geografía universal, fundamentos de la religión, exposición de dogmas y moral cristiana, ortografía, ortología y métrica castellana, lengua francesa, álgebra elemental, geometría elemental, Geografía física y política de las cinco partes del mundo y especial de Colombia, lengua inglesa, historia universal, historia patria, física, química, elementos de anatomía y fisiología humana, principios de biología y sociología, ideología y lógica. En lo referente a la Facultad de Jurisprudencia, debían explicarse las Cátedras de Economía Política, Ciencia de la Legislación Civil y Penal, Ciencia Constitucional y Administrativa, Derecho Constitucional y Derecho Administrativo, Derecho Romano explicado históricamente como resultado de las costumbres y civilización romana, Derecho Civil Español y Nacional, Derecho Civil Cundinamarqués, Derecho Internacional Público y tratados públicos, Derecho Internacional Privado e Historia del mismo, procedimientos Judiciales del Estado y de la Unión, pruebas judiciales y organización judicial y práctica forense. ${ }^{120}$

\footnotetext{
118 Decreto 129, 25 de febrero, 1882. Art. $4^{\circ}$ Diario Oficial No. 5285 de 28 de febrero, 1882. "por el cual se reorganiza el régimen interior del Colegio Mayor de Nuestra Señora del Rosario sobre las bases de las constituciones del fundador". Diario Oficial No. 5285,28 de febrero 28, 1882. Para conformar la junta fueron designados Juan Agustín Uricoechea, Venancio G. Manrique, Hermógenes Durán, Medardo Rivas, Emilio Hamon, Roberto Díaz, Aureliano González, Clímaco Calderón, Juan Nepomuceno Mateus, Eladio Vergara, Juan de la Cruz Santamaría, Aristides Forero, Facundo Mutis D., Ramón A. Corral y Francisco de P. Torres. Artículo 2 ib. 119 Ibid., Art. 3.

120 Ibid., 4
} 
Para completar la reorganización del Colegio el Presidente reiteró la atribución que le correspondía para el nombramiento de catedráticos, ${ }^{121}$ la que ejerció mediante un decreto de la misma fecha. ${ }^{122}$

El reglamento de administración de los bienes y rentas del Colegio, expedido el 31 de octubre de 1871 por el Gobernador del Estado de Cundinamarca regiría en todas sus partes a partir del siguiente mes. ${ }^{123}$

Aparte de otros puntos relativos a temas financieros ${ }^{124} \mathrm{y}$ administrativos, ${ }^{125}$ el decreto de reorganización señaló que en adelante el personal del Colegio se renovaría en la forma dispuesta por sus "instituciones fundamentales" y que en todo lo demás continuaría rigiéndose por las Constituciones que le dejó su fundador, en lo que ellas no fuesen contrarias a las instituciones de la República.

Igualmente, se derogaron las disposiciones anteriores sobre la organización y régimen del Colegio y se encargó a la Consiliatura la expedición de los reglamentos necesarios para la marcha de la institución los que, en todo caso, debían someterse a la aprobación del Patrono. ${ }^{126}$ Un par de días después el Rector del Colegio Juan Manuel Rudas sometió a la aprobación del Poder Ejecutivo Nacional el "Reglamento de Estudios del Colegio Mayor de Nuestra Señora del Rosario", ${ }^{127}$ cuya aprobación fue impartida inmediatamente. El Decreto 129 fue adicionado durante el mismo año de su expedición por el Decreto 315. ${ }^{128}$

\section{1. "La Regeneración" y la incorporación del Colegio a la Univer- sidad Nacional}

Con una nueva guerra civil, la de 1885 , se produjo el cierre de la Universidad Nacional. Su posterior reapertura implicó algunas modificaciones que incidieron directamente en la institucionalidad del Colegio del Rosario. El regreso de los jesuitas al país forzó la devolución del Colegio de San

121 Ibid., artículo 5.

122 Decreto No. 130, 25 de febrero, 1882. En Diario Oficial No. 5285, 28 de febrero, 1882.

123 Decreto No. 129, 25 de febrero, 1882, artículo 14.

124 Ibid., artículos 12, 13, 14 y 16.

125 Ibid., artículos $6,7,8,10,11,15$.

126 Ibid., artículos 16, 18, y 9 .

127 Texto completo del Reglamento en el Diario Oficial No. 5285, 28 de febrero, 1882, suscrito por el Rector Rafael Rudas, aprobado por el Presidente Rafael Núñez y el Secretario de Instrucción Pública Carlos E. Sáenz.

128 Decreto No. 315, 17 de mayo, 1882. Diario Oficial No. 5366, 29 de mayo 1882, 10516. 
Bartolomé a dicha comunidad, lo que obligó el traslado de las escuelas de Jurisprudencia, de Literatura y la de Filosofía al Colegio del Rosario. ${ }^{129}$

El decreto 544 del 14 de agosto de 1885 incorporó el Colegio del Rosario a la Universidad Nacional con el propósito expreso por parte del Gobierno de asegurar el carácter católico del Colegio bajo el patronato del Presidente de la República. ${ }^{130}$

Incorporado el Colegio a la Universidad, Carlos Martínez Silva, dirigente y uno de los ideólogos más conspicuos del partido conservador, fue nombrado Rector ${ }^{131}$ y desempeñó el cargo hasta el año 1888 cuando fue reemplazado por el también conservador José Manuel Marroquín.

Este período conservador implicó el desplazamiento de los liberales de la instrucción profesional de carácter público, lo que se tradujo en la fundación de la Universidad Externado de Colombia en febrero de $1886,{ }^{132}$ bajo el auspicio de intelectuales y dirigentes del liberalismo radical e, igualmente, de la Universidad Republicana ${ }^{133}$ por Luis Antonio Robles, un abogado proveniente de la Costa Caribe egresado del Colegio del Rosario.

Luego del levantamiento de los radicales en 1885 durante el segundo período de Rafael Núñez como Presidente de la Unión ${ }^{134}$ y de la posterior derrota de la rebelión, fue convocado un Consejo Nacional de Delegatarios con la función de deliberar acerca de los términos en los que debería procederse a la reforma de la Constitución. ${ }^{135}$ El Consejo Nacional de Delegatarios se transformó en el Consejo Nacional Legislativo que expidió la Ley 12 de $1886,{ }^{136}$ cuyo artículo primero autorizó al Gobierno para organizar la instrucción pública nacional.

\footnotetext{
129 Villamil, op cit., 41.

130 Ver: "Informe que el Secretario de Instrucción pública nacional presenta al H. Consejo de Delegatarios, sobre la incorporación del Colegio Mayor de Nuestra Señora del Rosario a la Universidad Nacional”. Diario Oficial No. 6.545, 21 de diciembre, 1885.

131 Decreto 875, 19 de diciembre, 1885

132 Fundada por Nicolás Pinzón Warlosten.

133 Que posteriormente se convertiría en la Universidad Libre bajo la tutela del General liberal Benjamín Herrera.

134 Ver Julio Palacio, “La Revolución de 1885”, Editorial Cromos, 1936. Gonzalo España, La Guerra civil de 1885 (Bogotá: El Áncora Editores, 1985),

135 Decreto 594, 10 de septiembre, 1885.

136 Ley 12 , 19 de agosto, 1886, sancionada por el Presidente José María Campo Serrano y el Ministro de instrucción Pública José Domingo Ospina C, en Leyes de la República de Colombia Expedidas por el Consejo Nacional Legislativo en sus sesiones de 1886 (Bogotá: Imprenta de Zalamea Hermanos, 1886), 30. Fue derogada por la ley 89 de 1888.
} 
En el mes de octubre del año de 1886, durante la Rectoría de Carlos Martínez Silva, ${ }^{137}$ el Presidente José M. Campo Serrano expidió el Decreto 596 de $1886^{138}$ regulando la instrucción pública secundaria y profesional que, fundándose en las autorizaciones conferidas al Ejecutivo por la referida ley 12, incorporó el Colegio del Rosario a la Universidad Nacional.

Según el decreto 596 la Universidad Nacional constaría de las facultades de Filosofía y Letras, Ciencias Matemáticas, Derecho, Ciencias Naturales y Medicina y Cirugía. Dispuso la incorporación a la Universidad de los institutos de instrucción gratuita secundaria existentes en los departamentos y de los colegios privados, entre estos el Colegio Mayor del Rosario, en donde se dictarían los cursos de la Facultad de Derecho.

Se dictarían igualmente en el Colegio del Rosario como cursos universitarios los correspondientes a la Facultad de Filosofía y Letras, teniendo el Colegio la atribución de conferir el título de Bachiller en Filosofía y Letras a los individuos que comprobaran ante el Ministerio de Instrucción Pública haber ganado o habilitado los cursos correspondientes a tal facultad.

También funcionaría en el Colegio del Rosario, mientras el Gobierno destinaba un local especial para tal fin, la facultad de Ciencias Matemáticas, sometida a los estatutos y reglamento interiores que regían en el Colegio. El Gobierno pagaría las asignaciones correspondientes a las facultades de Derecho y Ciencias Matemáticas y el Colegio pagaría los empleados particulares y los profesores de las asignaturas de Filosofía y Letras así como las de las demás que estableciera. ${ }^{139}$

El reglamento interno de la Facultad fue elaborado por el Rector de acuerdo con el "Reglamento Interior del Colegio del Rosario" y sometido a la aprobación del Gobierno.

Posteriormente, en mayo de 1887 el Gobierno se hizo cargo de los profesores de la Facultad de Filosofía y Letras, ${ }^{140}$ pero los empleados siguieron

137 Ver Miguel Antonio Caro, "Las Cuentas del Colegio del Rosario" en Obras Completas (Bogotá: Instituto Caro y Cuervo, 1962), 1444.

138 Decreto No. 596, 9 de octubre, 1886, en: Compilación de Normas sobre la Educación Superior, Vol. IV, parte I. (Bogotá: ICFES, 1974), 1035 y ss.

139 Decreto 596 de 1886.

140 Decreto 302 del 3 de mayo, 1887. En: Compilación de Normas sobre Educación Superior, Vol. IV, parte I (Bogotá: Ministerio de Educación Nacional, ICFES, 19749), 1054 y 1055. 
pagándose con fondos del Colegio. Las asignaturas de las facultades de Ciencias Matemáticas y Derecho las proveería el Gobierno directamente la primera vez y posteriormente de ternas presentadas por los Consejos de las facultades. Se le asignó a la Consiliatura la función de cuerpo consultivo del Rector en materia de gastos y de inversiones o colocación de los bienes pertenecientes al Colegio.

Las cátedras de las facultades de Filosofía y Letras serían provistas por la Consiliatura del Colegio de ternas presentadas por el Rector. A su turno este y los consiliarios serían nombrados por el Gobierno. El Rector nombraría libremente los empleados interiores del establecimiento y sería el encargado de dictar el reglamento interior del Colegio "calcándolo", hasta donde las circunstancias lo permitieran, de las Constituciones y de las prácticas antiguas de la institución, lo cual en todo caso debería someterse posteriormente a la aprobación del Gobierno.

El Colegio del Rosario conservaría la obligación de pagar a sus empleados particulares y a los profesores de las asignaturas de Filosofía y Letras, única Facultad propia con la que quedó el Colegio pues, en efecto, mientras las asignaturas de las Facultades de Ciencias Matemáticas y Derecho se proveerían directamente por el Gobierno, las de Filosofía y Letras, como quedó dicho, serían proveídas por la Consiliatura del Colegio de ternas que le presentaría el Rector para tal fin.

En lo relacionado con el aspecto administrativo, el Decreto 596 se ocupó tanto del Rector y de la Consiliatura del Colegio como del régimen de sus gastos. ${ }^{141}$ En relación con el Rector, dispuso que fuera nombrado por el Gobierno y que durara en el ejercicio de sus funciones durante todo el tiempo que observara, a juicio del Gobierno, buena conducta. Como quedó anotado, el Rector tendría la Facultad de nombrar libremente los empleados y de dictar el reglamento interior del Colegio el cual debía someter a la aprobación del Gobierno. ${ }^{142}$

También los consiliarios serían de nombramiento del Gobierno para períodos de dos años, quienes debían en lo posible ser escogidos entre las per-

141 Seguramente influyó para la inclusión de una regulación relativa al régimen de gastos la controversia surgida entre Miguel Antonio Caro y el Rector Rudas en torno a la rendición de cuentas de este último al entregar la rectoría. Ver Miguel Antonio Caro, "Las Cuentas del Colegio del Rosario" en Obras Completas (Bogotá: Instituto Caro y Cuervo, 1962), 1444.

142 Decreto 596 de 1886, artículos 31 y 33. 
sonas que hubieran recibido educación en el Colegio. El carácter de cuerpo consultivo asignado a la Consiliatura implicaba que el Rector no podía hacer gastos, invertir o colocar los bienes pertenecientes al Colegio sin autorización expresa de aquel cuerpo. Además, para la seguridad de los fondos a su cargo, el Rector del Colegio debía prestar una fianza personal o hipotecaria que, a juicio y satisfacción del Ministro de Instrucción Pública, garantizara su responsabilidad. En este mismo sentido, se prescribió que el Rector del Colegio debía rendir cuentas de su administración el 31 de diciembre de cada año, las que serían fenecidas en primera instancia por la Consiliatura y, en segunda, por la Corte de Cuentas.

Al año siguiente de expedido el Decreto sus disposiciones referentes al pago de los profesores de las asignaturas correspondientes a la Facultad de filosofía fueron modificadas. ${ }^{143}$ Para la modificación el Presidente de la República tuvo en cuenta tres consideraciones, una de las cuales fue el hecho de que "en el Colegio Mayor de Nuestra Señora del Rosario se dan además de las de Derecho, las enseñanzas correspondientes a la Facultad de Filosofía y Letras de la Universidad Nacional", razón por la cual se determinó que el pago de los profesores de las asignaturas correspondientes a tal Facultad correría, desde el mes de abril de 1887, por cuenta del Gobierno.

La incorporación del Colegio a la Universidad Nacional se reiteró en el año siguiente cuando el Rector José Manuel Marroquín celebró un contrato con el Ministro de Instrucción Pública, José Domingo Ospina, ${ }^{144}$ en virtud del cual el Rector se obligó a realizar algunas mejoras locativas en el Colegio con dineros entregados por el Gobierno que los pagaba "teniendo en cuenta que el Colegio de que se trata está incorporado en la Universidad Nacional, la que tiene allí sus clases de las Facultades de Filosofía y Letras y de Derecho...". ${ }^{145}$

Un año después, en 1889, se segregó del Colegio Mayor de Nuestra Señora del Rosario la Facultad de Derecho de la Universidad Nacional, ${ }^{146}$ quedando

143 Decreto No. 302 del 3 de mayo, 1887. En Compilación de Normas sobre la Educación Superior (Bogotá: ICFES, 1974), 1054 y 1055. El Decreto fue sancionado por el Presidente Eliseo Payán y por su Ministro de Instrucción Pública Carlos Martínez Silva. Al parecer para este momento ya había salido del Colegio la Facultad de Ciencias matemáticas, pues es mencionada en el texto del Decreto.

144 El Contrato fue suscrito el 31 de enero, 1888 y aprobado el 12 de febrero del mismo año por el presidente Núñez y su Ministro de Instrucción Pública, José Domingo Ospina. Posteriormente la Ley 34 del 27 de febrero, 1888, emanada del Consejo Nacional Legislativo y sancionada por Núñez, aprobó el contrato, en: Leyes de la República de Colombia expedidas por el Consejo Nacional Legislativo en sus sesiones de 1888 (Bogotá: Imprenta de Zalamea Hermanos, 1988), 122.

$145 \mathrm{El}$ artículo $8^{\circ}$ de la Ley 92 del 13 noviembre, 1888 reiteró que "los colegios que reciban subvención del Gobierno quedarán incorporados a la Universidad Nacional y sujetos a sus reglamentos y a la suprema inspección del Gobierno".

146 Decreto No. 62 del 29 de enero, 1889. Diario Oficial, 1889, 127. AHCR Vol. 72. Fols. 269-270. 
constituido en la Facultad de Filosofía y Letras de esta. Se dispuso igualmente que la Consiliatura del Colegio ejerciera sus funciones subordinada a la autoridad del Gobierno, que se reservó el poder de aprobar o desaprobar sus actos. ${ }^{147}$ Se dispuso además la fundación del Colegio Menor de Nuestra Señora del Rosario para la enseñanza de los alumnos menores de 15 años, el cual tendría la categoría de Liceo.

El artículo 55 del Decreto 1238 del primero de enero de 1892 dispuso que "Por el Colegio Mayor de Nuestra Señora del Rosario se concederá el grado de Doctor en Filosofía y Letras a los alumnos que hayan obtenido el título de Bachiller y ganen los cursos a que se refiere el artículo 19".

\title{
12. Nueva autonomía y Constituciones Nuevas
}

En Diciembre de 1892 el Presidente de la República sancionó la ley 89 sobre instrucción pública, la que en su artículo décimo dispuso que

\begin{abstract}
Al Colegio Mayor de Nuestra Señora del Rosario se le reconoce su autonomía quedando bajo el patronato del Gobierno. En consecuencia, el Rector será de libre nombramiento y remoción del Presidente de la República y seguirán rigiendo las Constituciones del Colegio, con las modificaciones que los tiempos reclamen y que se introduzcan con arreglo a lo que por ellas mismas está previsto. Por mutuo acuerdo entre la Consiliatura y el Gobierno, el Colegio podrá continuar con el carácter de Facultad de Filosofía y Letras... ${ }^{148}$
\end{abstract}

Unos días después se expidió el decreto reglamentario u "Orgánico de la Instrucción Pública", ${ }^{149}$ cuyo artículo séptimo dispuso que la Facultad de Letras y Filosofía se radicase en el Colegio del Rosario, al cual se le dedica íntegramente su Capítulo VIII, que no presenta reformas sustanciales en relación con lo dispuesto en el Decreto 596 de 1886. Quizá la modificación más importante es la contenida en el artículo 38 en el que se señalaba que conforme a lo dispuesto por el artículo 10 de la Ley 89 de 1892, sobre Instrucción Pública, el Colegio Mayor de Nuestra Señora del Rosario se organizaría y regiría por las Constituciones dictadas por su fundador, con

147 El 14 de abril, 1890 se dictó el Decreto No. 157, cuyo artículo único suspendió las tareas de la Facultad de Derecho de la Universidad Nacional señalando que "Oportunamente se avisaría al público que día se organiza y cuáles son las condiciones que se requieren para que se matriculen los alumnos que deban cursar en ella".

148 Artículo 10 de la ley 89 del 13 de diciembre, 1892, sancionada por el Presidente Miguel Antonio Caro y por el Ministro de Instrucción Pública, Liborio Zerda, quien más adelante sería Consiliario del Colegio.

149 Decreto Número 349 del 31 de diciembre, 1892. 
las modificaciones que fuese necesario introducir en ellas, y en relación con los progresos que se hubiesen alcanzado en las letras y en las ciencias.

Respecto al nombramiento del Rector no dispuso ninguna variación, pues continuaría siendo designado por el "Gobierno", Patrono del Colegio, que también nombraría los Consiliarios, quienes desempeñarían sus funciones por períodos de dos años. A la Consiliatura se le reiteró su carácter de cuerpo consultivo del Rector, integrada por tres Consiliarios, el Vicerrector y el Rector, que la presidiría. Se reiteró igualmente que el Rector no podía hacer gastos, invertir ni colocar los bienes pertenecientes al Colegio sin autorización expresa de la Consiliatura.

Como novedad, se indicó que la administración de los bienes y el apoyo material de los gastos del Colegio correspondían al Síndico, el cual actuaría bajo la inspección del Rector. El nombramiento de este funcionario, que debía durar un año en sus tareas sin poder ser reelegido para el período inmediato, correspondía a la Consiliatura. Debía asegurar su gestión con una fianza personal o prendaria o con una hipoteca en montos estipulados en el Decreto.

El 16 de Febrero de 1892 Miguel Antonio Caro, como Vicepresidente de la República encargado del Poder Ejecutivo, había nombrado al Presbítero Rafael María Carrasquilla como Rector. La facultad de libre nombramiento y remoción del Rector asignada en la ley 92 rigió hasta 1930, cuando por virtud del acuerdo de la Consiliatura del Colegio, aprobado por el Gobierno Nacional, se volvió al régimen electivo consagrado en las Constituciones del fundador.

El día 4 de abril de 1893, Miguel Antonio Caro, en ejercicio del Patronato Presidencial sobre el Colegio, aprobó las Constituciones Nuevas del Colegio Mayor de Nuestra Señora del Rosario.

En desarrollo del artículo 10 de la ley 89 de 1892, que dispuso que por mutuo consenso entre la Consiliatura y el Gobierno, el Colegio podría continuar con el carácter de facultad de Filosofía y Letras, se celebró un acuerdo el 20 de Abril de 1893 en el que se reiteró la autonomía del Colegio y la disposición 
de que se rigiera por sus Constituciones. Su facultad de Filosofía y Letras conservó su carácter y validez de facultad universitaria para efectos de grados, diplomas y demás consecuencias profesionales de sus estudios.

En septiembre del mismo año se autorizó al Colegio para conceder el diploma de Bachiller ${ }^{150}$ y en 1894 se afirmó la exclusividad de los Colegios de San Bartolomé y el Rosario para conceder el bachillerato y doctorado en Filosofía y Letras "por la extensión y calidad de sus asignaturas y por constituir la facultad de aquel nombre." 151

El reglamento sobre los requisitos para obtener los referidos grados lo estableció la Consiliatura mediante el acuerdo de 24 de febrero de 1893.

\section{CONCLUSIÓN}

Durante el siglo XIX el Estado colombiano, al tiempo que intentó poner en pie un sistema educativo que consideró necesario para la formación de los cuadros republicanos y la introducción de algunos de los elementos de la nueva racionalidad moderna, se enfrentó a la precariedad de recursos económicos y, en su interior, al enfrentamiento de diversas visiones sobre lo que debía ser la educación, si debía centralizarse su dirección o si, incluso, debían suprimirse los títulos profesionales.

En este contexto, una mirada diacrónica a la institucionalidad legal de uno de los establecimientos educativos que provenía de la Colonia y que desarrolló una compleja relación con el Estado decimonónico, permite trazar las grandes líneas sobre las que se desarrolló el proyecto educativo republicano durante el siglo XIX, entre las cuales pueden identificarse las tensiones entre laicización y las corrientes tradicionalistas, la inicial tendencia centralizadora y estatizadora enfrentada a la carencia de recursos públicos para echar a andar un sistema nacional de educación sobre los recursos todavía disponibles de los establecimientos educativos heredados de la colonia.

El Colegio del Rosario fungió como vivero privilegiado de la nueva burocracia estatal, que algunas veces intercedió en favor de su institucionalidad y de

150 Decreto 1342,1893 , artículo $1^{\circ}$.

151 Resolución No. 4 de febrero $1^{\circ}$ de 1894. 
su autonomía. Su gran capital simbólico y su armazón jurídica fundacional le sirvieron para resistir los múltiples intentos de incorporación como institución estatal pero, a su vez lo predispuso como un espacio importante de contienda entre quienes se disputaban diversas clases de poder.

Es importante resaltar que las disputas por la institucionalidad del Rosario fueron de diverso carácter, por lo que se presentaron desde actuaciones de hecho del poder público hasta contiendas administrativas y judiciales en las que terminó decidiéndose de variadas formas la suerte de su autonomía.

\section{FUENTES}

AHCR Vol. 43. Fol. 227.

AHCR Vol. 43. Fol. 209.

AHCR, Miscelánea, Volumen 59, Folio 110

ALC Senado. 1827. Tomo XLI. Peticiones, fols. 164 a 181Decreto enero 5 de 1822$\}$

Archivo General de la Nación (AGN), Sección República. Fondo Instrucción Pública. Tomo 111. Fol. 646.

Decreto de 18 de Marzo, 1826

Decreto 3 de octubre, 1826

Decreto del 20 de Octubre, 1826

Decreto 5 de Marzo, 1827

Decreto de diciembre 5 de 1829

Decreto 24 de Diciembre, 1838

Decreto 7 de Julio, 1840.

Decreto diciembre 20, 1844.

Decreto Agosto 24, 1861.

Decreto No. 771 de 1880.

Decreto No. 36, 25 de enero, 1881.

Diario Oficial No. 4929, 28 de enero, 1881 
Diario Oficial 4938 de 8 febrero, 1881

El Diario Oficial No. 5255, 25 de enero, 1882

Diario Oficial No. 5285, 28 de febrero, 1882

Gaceta de Colombia No. 266 del 19 de Noviembre, 1826. Trimestre 22

Gaceta de Colombia No. 278 del 11 de febrero, 1827.

Gaceta de Colombia No. 314 del 21 de octubre, 1827

Gaceta de Colombia No. 319 del 25 de noviembre, 1827.

Gaceta de Colombia No. 322 del 16 de diciembre, 1827.

Gaceta de Colombia 390 del 14 de diciembre, 1828.

Gaceta de Colombia 390 del 14 de diciembre, 1828.

Gacetas de Colombia. Nos. 469 del 13 de junio, 470 del 20, junio, 471 del 27 de junio y 474 del 18 de julio, 1830.

Ley 20 de junio, 1821

Ley de 6 de agosto, 1821

Ley 18 de marzo, 1826

Ley 16 de Mayo, 1840.

Ley 15 de Mayo, 1841

Ley 21 de mayo, 1842

Ley $6^{\circ}$ del 10 de marzo, 1953

Ley 41 de mayo 29, 1864

Ley Febrero 9, 1865.

\section{REFERENCIAS}

Álvarez de Morales, Antonio. Génesis de la universidad española contemporánea. Madrid: Instituto de Estudios Administrativos, 1972.

Bushnell, David. El Régimen de Santander en la Gran Colombia. Bogotá: El Áncora Editores, 1985. 
Caro, Miguel Antonio. “Las cuentas del Colegio del Rosario”, en La Nación, Año IV No. 402 (1889): 2. Reproducido en Miguel Antonio Caro, Obras. Bogotá: Instituto Caro y Cuervo, 1962.

Condorcet, Nicolás de Caritat, Marqués de. La Instrucción Pública. Catalonia: Eumo Editorial, 1996.

Gaitán Bohórquez, Julio. Huestes de Estado. La formación universitaria de los juristas en los comienzos del Estado Colombiano. Bogotá: Editorial Universidad del Rosario, 2002.

Le Goff, Jacques. Los intelectuales en la Edad Media. Barcelona: Gedisa, 1996.

Mora, Luis María. Croniquillas de mi ciudad. Bogotá: Banco Popular, 1972.

Osorio Racines, Felipe. Decretos del General Santander. 1819-1821. Bogotá: Universidad Nacional, 1969.

Peset, Mariano. (Dirección y prólogo) Claustros y Estudiantes. Congreso internacional de historia de las universidades americanas y españolas en la edad moderna. Valencia: Facultad de Derecho de la Universidad de Valencia, 1989.

Rivas, Rafael. "La autonomía del Colegio del Rosario defendida por su Rector don Rafael Rivas en 1859". Revista del Colegio Mayor de Nuestra Señora del Rosario No. 289-290 (1934): 462-493.

Rocha Alvira, Antonio. "Autonomía Privada del Colegio del Rosario". Revista del Colegio Mayor de Nuestra Señora del Rosario, Vol. LXXI, 489(1971).

Silva, Renán. Universidad y Sociedad en el Nuevo Reino de Granada, Bogotá: Banco de la República, 1992.

Villamil Ardila, Carol. Aproximación histórica a la Facultad de Derecho, Ciencias Políticas y Sociales de la Universidad Nacional de Colombia. Bogotá: Universidad Nacional de Colombia, 2001.

Wise De Gouzy, Doris. Antología del Pensamiento de Mariano Ospina. Bogotá: Colección Bibliográfica del Banco de la República, 1990.

Gaitán Bohórquez, Julio. "La difusa autonomía. El Colegio del Rosario en los proyectos de universidad pública del siglo XIX colombiano". Revista Historia de la Educación Latinoamericana. Vol. 15 No, 21, (2013): 107 - 159. 